\title{
DESIGNING AND DETAILING TRANSVERSE REINFORCEMENT TO CONTROL BAR BUCKLING IN RECTANGULAR RC WALLS
}

\author{
Mayank Tripathi ${ }^{1}$ and Rajesh P. Dhakal ${ }^{2}$
}

(Submitted September 2020; Reviewed October 2020; Accepted November 2020)

\begin{abstract}
Bar buckling in RC structures is a commonly-observed failure mode that adversely affects their deformation capacity. To restrict bar buckling in ductile $\mathrm{RC}$ walls, design codes only emphasises on restricting the spacing of transverse reinforcement and does not recognise the importance of the effective stiffness of the ties (which is a combination of the tie leg axial stiffness and spacing) to restrict bar buckling. Therefore, in this paper the design requirements for anti-buckling transverse reinforcement are summarised, and improvements to the current design methodology for anti-buckling transverse reinforcement are proposed. To ensure that the transverse reinforcement detailing in plastic hinge regions is adequate to restrict bar buckling to single tie spacing and the compressive stress deterioration in bars due to buckling is controlled, refinements to the current detailing procedures are proposed. The buckling restraining ability of transverse reinforcement depends on the axial stiffness of the tie legs, while the compressive stress reduction in reinforcing bars due to buckling depends on their unsupported length (in bare bar tests) or buckling length that can include multiple tie spacing (inside RC members). Therefore, restrictions on both the axial stiffness of the tie legs and spacing of transverse reinforcement along the longitudinal reinforcing bars are proposed. The effective axial stiffness of tie legs is controlled by ensuring that the length of the tie legs in the direction of potential buckling is well below the critical length evaluated using a mechanics-based approach. Additionally, compressive stress degradation in reinforcing bars is controlled by limiting the ratio of the transverse reinforcement spacing and the longitudinal bar diameter such that any reduction of compressive stress carried by the longitudinal bars due to buckling at the limiting curvature recommended by New Zealand Concrete Standard is within an acceptable range. Furthermore, recommendations to avoid buckling of unrestrained reinforcing bars in the boundary zone and the wall web are proposed. Using the proposed design methodology, buckling of longitudinal reinforcing bars in ductile RC walls can be delayed and the detrimental effects of buckling on the lateral response of walls can be controlled until the design drift or curvature demands are met.
\end{abstract}

\section{INTRODUCTION}

Reinforced concrete (RC) walls are prevalent lateral loadresisting systems used in medium- to high-rise buildings around the world. The past earthquakes in Chile (2010) and New Zealand (2010-11) have demonstrated the criticality of RC walls and highlighted the shortcomings in the existing wall design guidelines. The critical failure modes of $\mathrm{RC}$ walls witnessed in these earthquakes included global buckling of walls, buckling of reinforcing bars, crushing of toes of walls and shear failure. Of these observed failure modes in slender $\mathrm{RC}$ walls, failure associated with reinforcement buckling was one of the most widely-observed mechanisms, triggering the overall failure of RC walls [1,2]. In addition, bar buckling has been observed during experimental tests on $\mathrm{RC}$ walls reported in the literature [3-9].

When subjected to lateral loading, RC structures exhibit cracking; thereafter, resulting in net tensile forces to be resisted mainly by reinforcing bars with just a small fraction of the tensile forces being resisted by the uncracked concrete. When the lateral load is reversed, due to the presence of residual cracks in the concrete along with reinforcement elongation, the entire compressive force needs to be resisted by reinforcing bars alone until the cracks close. If these reinforcing bars are not effectively restrained in the lateral direction using anti-buckling reinforcement, they are bound to buckle, followed by the abrupt closure of the cracks in the compression region; thereby transferring huge compressive stresses to concrete and subsequently leading to its crushing. Most design codes recommend providing transverse reinforcement within the plastic hinge regions to enable the structures to undergo large inelastic deformations. The transverse reinforcement in RC structures is designed to serve three main purposes: (i) to provide shear strength; (ii) to provide confinement to concrete in the plastic hinge regions; and (iii) to restrain longitudinal bars against buckling. In ductile RC walls, transverse reinforcement in the form of stirrups and ties is mainly designed to confine the concrete within the end regions of the wall and to restrict buckling of longitudinal reinforcing bars in these boundary zones.

Buckling of reinforcing bars results in the reduction of compression capacity of reinforcing bars $[10,11]$ and is mainly caused due to inferior detailing of transverse reinforcement in $\mathrm{RC}$ structures. In a typical RC member, buckling of longitudinal reinforcing bars can span multiple tie spacing, depending on the effective lateral restraint (governed by the spacing and stiffness) of the transverse reinforcement [12]. Contrary to this, modern design codes only emphasise on the spacing of transverse reinforcement as the major criterion for providing lateral resistance against buckling. In addition, premature compressive stress degradation due to buckling under cyclic loading (i.e. bar buckling while still carrying tensile strains) is generally ignored by assuming that buckling only initiates at high compressive

1 Corresponding Author, Post-doctoral Research Associate, Quake Centre, University of Canterbury, Christchurch, mayank.tripathi@canterbury.ac.nz (Young Professional Member).

2 Professor, University of Canterbury, Christchurch, rajesh.dhakal@canterbury.ac.nz (Fellow) 
strain demands. However, it is evident from cyclic tests on reinforcing bars that when subjected to cyclic loading, bars might buckle in the tensile strain region while the stresses are compressive in nature $[13,14]$. This ignorance of cyclic strain demands on the hysteretic response of reinforcing bars leads to over-prediction of the inelastic lateral deformation capacity of $\mathrm{RC}$ structures, thereby potentially leading to weaker and unsafe structures. In addition to bar buckling, bar fracture due to the accumulation of low-cycle fatigue damage has also been commonly observed in RC walls and columns. Although the accumulation of low-cycle fatigue damage in reinforcing bars cannot be avoided, the detrimental effect of fatigue damage on the hysteretic response of bars and their subsequent fracture can be delayed by either limiting the strain demands at plastic hinges by designing the RC structural elements for low ductility demands or by limiting the buckling of reinforcing bars to single tie spacing $[15,16]$.

In this paper, current guidelines for the design of anti-buckling transverse reinforcement in different design codes are summarised and compared. The limitations of current design methodologies to restrain bar buckling within single spacing are highlighted, and improved design guidelines for anti-buckling transverse reinforcement are proposed to limit bucklinginduced compressive stress degradation under cyclic loading within acceptable range.

\section{DESIGN OF TRANSVERSE REINFORCEMENT IN RC WALLS}

To achieve a ductile wall response until the design drift demand is reached, design codes [17-20] recommend that wall boundary regions that are susceptible to compression yielding should be detailed with adequate confinement reinforcement and the longitudinal reinforcing bars should be restrained against buckling. For adequate confinement within the boundary zones of walls, design codes recommend requirements to ensure that the volumetric transverse reinforcement ratio is adequate to confine the core concrete. For example, NZS3101:2006 [17] suggests that concrete within the boundary regions of walls that are susceptible to compression yielding shall be provided with transverse reinforcement whose cross-sectional area $\left(\mathrm{A}_{\text {sh }}\right)$ is given by Equation 1:

$$
\mathrm{A}_{\mathrm{sh}} \geq \alpha \operatorname{sh}_{\mathrm{c}} \frac{\mathrm{A}_{\mathrm{g}}}{\mathrm{A}_{\mathrm{c}}} \frac{\mathrm{f}_{\mathrm{c}}^{\prime}}{\mathrm{f}_{\mathrm{yt}}}\left(\frac{\mathrm{c}}{\mathrm{L}_{\mathrm{w}}}-0.07\right)
$$

where $\alpha=0.25$ for ductile plastic regions, $s$ is the centre-tocentre spacing of hoops, $h_{c}$ is the dimension of concrete core in the direction perpendicular to the direction of hoop, $A_{g}$ is the gross area of concrete, $A_{c}$ is the area of concrete core, $f_{c}{ }^{\prime}$ is the compressive strength of concrete, $f_{y t}$ is the yield strength of the transverse reinforcement, $c$ is the neutral axis depth and $L_{w}$ is the wall length.

Similarly, ACI-318 [18] suggests that the special boundary elements of RC walls shall be provided with transverse reinforcement with a total cross-sectional area, $\mathrm{A}_{\mathrm{sh}}$, given by Equation 2:

$$
\mathrm{A}_{\mathrm{sh}} \geq \max \left\{\begin{array}{c}
0.3 \mathrm{sh}_{\mathrm{c}}\left(\frac{\mathrm{A}_{\mathrm{g}}}{\mathrm{A}_{\mathrm{c}}}-1\right) \frac{\mathrm{f}_{\mathrm{c}}{ }^{\prime}}{\mathrm{f}_{\mathrm{yt}}} \\
0.09 \frac{\mathrm{sh}_{\mathrm{c}} \mathrm{f}_{\mathrm{c}}}{\mathrm{f}_{\mathrm{yt}}}
\end{array}\right.
$$

Similarly, Eurocode-8 [20] also provides an expression to estimate the volumetric transverse reinforcement ratio required to ascertain that the boundary regions of walls have adequate strength and ductility in compression. As per Eurocode-8, the mechanical volumetric ratio of confining reinforcement, $\omega_{\mathrm{wd}}$, shall be given by Equation 3:

$$
\alpha_{c} \omega_{w d} \geq 30 \mu_{\phi}\left(v_{d}+\omega_{v}\right) \varepsilon_{s y, d} \frac{h^{\prime}}{h_{c}}-0.035
$$

where $\mu_{\phi}$ is the required curvature ductility, $\mathrm{v}_{\mathrm{d}}$ is the normalised design axial force (i.e. axial load ratio), $\omega_{\mathrm{v}}$ is the mechanical ratio of vertical reinforcement, $\varepsilon_{s y, d}$ is the design tensile yield strain, $h$ ' is the gross cross-sectional width, $h_{c}$ is the width of confined core and $\alpha_{c}$ is the confinement effectiveness factor.

In addition to the guidelines for concrete confinement, design codes prescribe requirements for anti-buckling transverse reinforcement. Design codes [17-20] recommend providing closely-spaced transverse reinforcement in the form of stirrups/ties to limit the buckling of longitudinal reinforcing bars in regions susceptible to compression yielding. For this purpose, the codes recommend that in ductile plastic hinge regions the spacing of transverse reinforcement should be less than $6 d_{b}$, where $d_{b}$ is the diameter of the longitudinal reinforcing bar being restrained.

NZS3101:2006 [17] suggests an analytical expression to evaluate the area of transverse reinforcement required for buckling resistance. According to NZS3101:2006 [17], the area of anti-buckling reinforcement can be evaluated using Equation 4 , where $A_{t e}$ is the area of each leg or cross tie in the direction of potential buckling, $\sum \mathrm{A}_{\mathrm{b}}$ is the sum of the area of longitudinal bars reliant on the tie leg, $s$ is the spacing of transverse reinforcement, $f_{y}$ is the yield strength of longitudinal reinforcing bars, $f_{y t}$ is the yield strength of transverse reinforcement and $d_{b}$ is the diameter of the longitudinal reinforcing bar being restrained by the tie. Similarly, ACI-318 [19] limits the minimum area of the tie bar required to enclose reinforcing bars of different diameter. According to ACI-318 [19], the diameter of the tie bar shall be greater than $9.53 \mathrm{~mm}$ for enclosing $32.3 \mathrm{~mm}$ or smaller diameter longitudinal bars and $12.7 \mathrm{~mm}$ for enclosing $35.8 \mathrm{~mm}$ or larger diameter longitudinal bars. Table 1 summarises the comparison of anti-buckling guidelines prescribed in major international codes.

$$
A_{t e}=\frac{\sum A_{b} f_{y}}{96 f_{y t}} \frac{s}{d_{b}}
$$

As can be seen from Table 1, design codes agree on the spacing requirement for anti-buckling reinforcement; however, there is a lack of consistency in design codes regarding the area of antibuckling transverse reinforcement to restrict bar buckling. During previous earthquakes in New Zealand (2010-11), a significant number of slender RC walls suffered damage due to buckling of longitudinal reinforcing bars. As a result, intermediate guidelines for the design of anti-buckling ties were proposed [21]. These guidelines recommend that transverse reinforcement shall be provided along the entire wall length, as follows:

"Confinement of the boundary regions shall be provided in accordance with NZS3101:2006 [17], clause 11.4.6 - modified to provide confinement over the full length of the compression zone.

Transverse reinforcement in the central portion of the wall shall satisfy the anti-buckling requirements of NZS3101:2006 [17], clause 11.4.6.3." 
Table 1: Comparative evaluation of different design codes for anti-buckling guidelines.

\begin{tabular}{|c|c|c|}
\hline \multirow{2}{*}{ Design code } & \multicolumn{2}{|c|}{ Anti-buckling reinforcement } \\
\hline & Spacing $(\mathbf{s})^{\mathbf{a}}$ & $\operatorname{Area}\left(\mathbf{A}_{\text {te }}\right)$ \\
\hline NZS3101:2006 [17] & $\mathrm{s} \leq\left\{\begin{array}{c}6 \mathrm{~d}_{\mathrm{b}} \text { DPR } \\
10 \mathrm{~d}_{\mathrm{b}} \text { LDPR }\end{array}\right.$ & $A_{t e}=\frac{\sum A_{b} f_{y}}{96 f_{y t}} \frac{s}{d_{b}}$ \\
\hline ACI-318 [19] & $\mathrm{s} \leq\left\{\begin{array}{c}6 d_{b} \\
152.4 \mathrm{~mm}\end{array}\right.$ & $\begin{array}{l}\text { Assumes that the confinement reinforcement } \\
\text { is adequate. However, recommends minimum } \\
\text { diameter of the tie bar. }\end{array}$ \\
\hline Eurocode-8 [20] & $\begin{array}{l}\text { No specific definition for anti-buckling } \\
\text { reinforcement }\end{array}$ & $\begin{array}{l}\text { Assumes that the confinement reinforcement } \\
\text { is adequate }\end{array}$ \\
\hline
\end{tabular}

${ }^{a}$ DPR (Ductile Plastic Hinges), LDPR (Limited Ductile Plastic Hinges)

Although these intermediate guidelines aim to improve the overall performance of RC wall systems, they do not aim to improve the buckling performance of longitudinal reinforcing bars in boundary regions of ductile $\mathrm{RC}$ walls.

All modern design codes agree on providing transverse reinforcement in the form of stirrups/ties to provide shear resistance and confinement to the core concrete, and design provisions for these two purposes have been developed based on extensive research carried out on RC members [22-25]. However, the provisions for anti-buckling reinforcement are somewhat vague and have been developed based on experience and intuition rather than a robust theoretical backup [26].

In a reinforcing bar subjected to monotonic compression, compressive stress degradation can be delayed by limiting the unsupported height of the reinforcing bars to less than six times the diameter of the bar. Therefore, the design codes restrict the spacing of transverse reinforcement to less than $6 \mathrm{~d}_{\mathrm{b}}$ and ignore the effect of cyclic loading on premature buckling of longitudinal reinforcing bars. In addition, the possibility of bar buckling spanning multiple tie spacing is not given due consideration in the design codes by presuming that the confinement reinforcement is always adequate to restrict the bar buckling between successive ties. However, past research has shown that this is inaccurate and if not quantified, can have serious repercussions on the seismic performance of $\mathrm{RC}$ structures [5,6]. For instance, in a RC member with transverse reinforcement spaced at $6 \mathrm{~d}_{\mathrm{b}}$, if the anti-buckling transverse reinforcement is inadequate to restrict bar buckling to single tie spacing, bar buckling can span multiple tie spacing (as shown in Figure 1), causing a significant reduction in compressive stresses at relatively small strain demands. For example, in a Grade 300E reinforcing bar with bar buckling spanning single and three tie spacing (i.e. slenderness ratios of 6 and 18) under monotonic compression only, stress deterioration starts at approximately 0.047 and 0.0015 compressive strain, respectively [14]. Therefore, the extent of bar buckling in terms of the buckling mode should be effectively considered in the design process. In addition, the effect of cyclic loading on premature buckling of reinforcing bars (i.e. bar buckling while carrying tensile strains) should be taken into account while limiting the spacing of transverse reinforcement.

\section{MECHANICS-BASED DESIGN OF ANTI-BUCKLING TRANSVERSE REINFORCEMENT}

To overcome the aforementioned limitations of modern design codes, researchers in the past have investigated the effectiveness of transverse reinforcement on restricting bar buckling in RC members [12,26-30]. Of these reported studies, the most widely-accepted research was carried out by Dhakal and Maekawa [12], from which a methodology for the design of anti-buckling transverse reinforcement for RC columns was recently proposed [26]. Dhakal and Maekawa [12] conducted extensive analytical studies on a beam-on-springs model, where the beam represented the longitudinal reinforcing bar, and elasto-plastic springs represented the tie legs restraining the bars against buckling. Based on these investigations, a relationship between the axial stiffness of the ties and buckling length of the longitudinal reinforcing bar was developed. Further, simplified equations were proposed to evaluate the buckling mode of reinforcing bars in RC structures. Using this analytical model, the buckling mode of reinforcing bars can be evaluated using Equations 5 and 6, where $\mathrm{k}_{\mathrm{t}}$ is the axial stiffness of a tie leg in the direction of potential buckling, $E_{t}$ is its elastic modulus, $A_{t}$ is its cross-sectional area, $l_{e}$ is the tie leg length, $n_{l}$ is the number of tie legs in the direction of potential buckling, $\mathrm{n}_{\mathrm{b}}$ is the number of longitudinal reinforcing bars reliant on $\mathrm{n}_{l}$ tie legs, $k_{n}$ is the required stiffness of the tie leg to restrain bar buckling, EI is the flexural rigidity of buckling-prone reinforcing bars (given by Equation 7), $\mathrm{E}_{\mathrm{S}} \mathrm{I}$ is the elastic bending stiffness of the longitudinal bar, $s$ is the spacing of transverse reinforcement and $\mathrm{k}_{\mathrm{eq}}$ is the equivalent stiffness coefficient for different buckling modes (given in Table 2). Therefore, using this model, the buckling of longitudinal reinforcing bars in RC structures can be restricted to single tie spacing by ensuring that the axial stiffness $\left(\mathrm{k}_{\mathrm{t}}\right)$ of the tie legs is greater than the critical stiffness $\left(\mathrm{k}_{\mathrm{n}}\right)$ required to restrict bar buckling to single tie spacing, as given by Equation 8 .

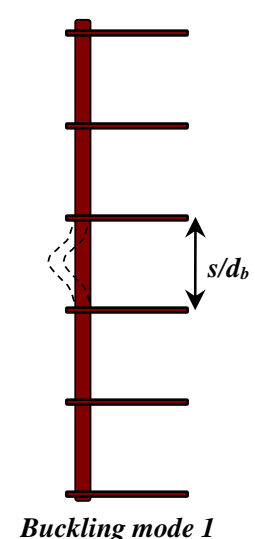

Buckling mode 1

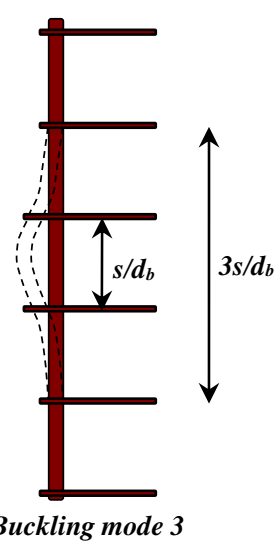

Buckling mode 3
Figure 1: Schematic layout of the buckling modes [5].

$$
\begin{aligned}
& \mathrm{k}_{\mathrm{t}}=\frac{\mathrm{E}_{\mathrm{t}} \mathrm{A}_{\mathrm{t}}}{\mathrm{l}_{\mathrm{e}}} \frac{\mathrm{n}_{\mathrm{l}}}{\mathrm{n}_{\mathrm{b}}} \\
& \mathrm{k}_{\mathrm{n}}=\mathrm{k}_{\mathrm{eq}} \frac{\pi^{4} \mathrm{EI}}{\mathrm{s}^{3}} \\
& \mathrm{EI}=\frac{\mathrm{E}_{\mathrm{s}} \mathrm{I}}{2} \sqrt{\frac{\mathrm{f}_{\mathrm{y}}}{400}}
\end{aligned}
$$


For Buckling mode-1:

$\mathrm{k}_{\mathrm{t}} \geq 0.75 \frac{\pi^{4} \mathrm{EI}}{\mathrm{s}^{3}}$

Table 2: Required tie leg stiffness coefficient for different buckling modes [12].

\begin{tabular}{cccccccc}
\hline $\begin{array}{c}\text { Buckling } \\
\text { mode }\end{array}$ & $\mathbf{1}$ & $\mathbf{2}$ & $\mathbf{3}$ & $\mathbf{4}$ & $\mathbf{5}$ & $\mathbf{6}$ & $\mathbf{7}$ \\
\hline keq & 0.75 & 0.1649 & 0.0976 & 0.0448 & 0.0084 & 0.0063 & 0.0038 \\
\hline
\end{tabular}

The analytical model proposed by Dhakal and Maekawa [12] has been validated by other researchers $[29,31]$ and is wellaccepted by the engineering community for evaluating the buckling length of reinforcing bars in RC structures. Therefore, in this study the stability model proposed by Dhakal and Maekawa [12] (referred to as the DM stability model) has been adopted for highlighting the limitations of transverse reinforcement requirement specified in current design codes. As NZS3101:2006 [17] is the only design code that recommends an expression for estimating the area of antibuckling ties, the discussion between the DM stability model and the design codes is limited to anti-buckling requirements recommended by NZS3101:2006 [17].

The difference between the anti-buckling requirement recommended by NZS3101:2006 [17] and the DM stability model is evaluated by comparing the anti-buckling requirements as per NZS3101:2006 [17] (Equation 4) and the diameter of transverse reinforcement required to restrict bar buckling to single tie spacing evaluated using Equation 8. For this purpose, the boundary zones of two RC walls designed according to NZS3101:2006 [17] are adopted and the diameters of tie legs required according to NZS3101:2006 [17] and Dhakal and Maekawa [12] are evaluated and compared. The boundary zones adopted here represent the boundary zone of wall RWB (tested by Dashti et al. [4]) and wall C10 (tested by
Shegay et al. [32]). Figure 2 and Figure 3 show the comparison of the tie requirements as per NZS3101:2006 [17] and Dhakal and Maekawa [12]. In these figures, the horizontal purple line represents the minimum bar diameter available for transverse reinforcement (i.e. $6 \mathrm{~mm}$ ). As can be seen from these figures, for both identified wall boundaries, the diameter required for anti-buckling reinforcement as per NZS3101:2006 is well below the minimum bar diameter available (i.e. $6 \mathrm{~mm}$ ). In addition, for the selected boundary zones with transverse reinforcement spacing less than $6 \mathrm{~d}_{\mathrm{b}}$, the values obtained using Equation 4 are significantly below the diameter of transverse reinforcement required to restrict buckling to single tie spacing evaluated using Equation 8.

This difference in diameter requirement (according to NZS3101:2006 [17] and Dhakal and Maekawa [12]) is mainly due to the fact that the two approaches follow entirely different philosophies for the design of anti-buckling transverse reinforcement. Increasing the spacing of transverse reinforcement reduces the demand imposed by the reinforcing bar undergoing buckling to the transverse reinforcement. Therefore, as the spacing of transverse reinforcement increases, the diameter of tie leg required to restrict bar buckling reduces. On the contrary, NZS3101:2006 [17] recommends reducing the area of transverse reinforcement required to restrict bar buckling as the spacing is decreased. This holds true for confinement reinforcement, as with reduced spacing the volumetric transverse reinforcement ratio increases; therefore, both strength and ductility of the confined concrete is enhanced, and consequently the lateral response of the structure is improved. However, reducing the spacing of transverse reinforcement increases the buckling-induced demands imposed by longitudinal reinforcing bars on transverse reinforcement, therefore requiring larger transverse reinforcement to restrain longitudinal bar buckling within single tie spacing. This explains why in walls tested in the literature $[3,5,6]$, providing closely-spaced stirrups resulted in increased buckling of longitudinal reinforcing bars.

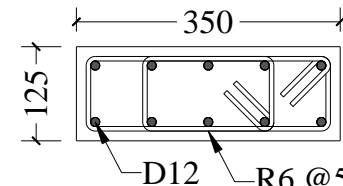

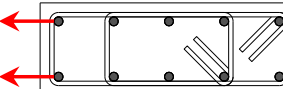

(b) Bar buckling in $\mathrm{X}$-direction

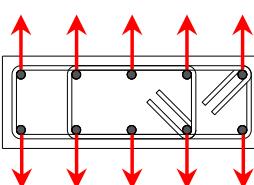

(c) Bar buckling in Y-direction (a) Boundary zone of wall RWB

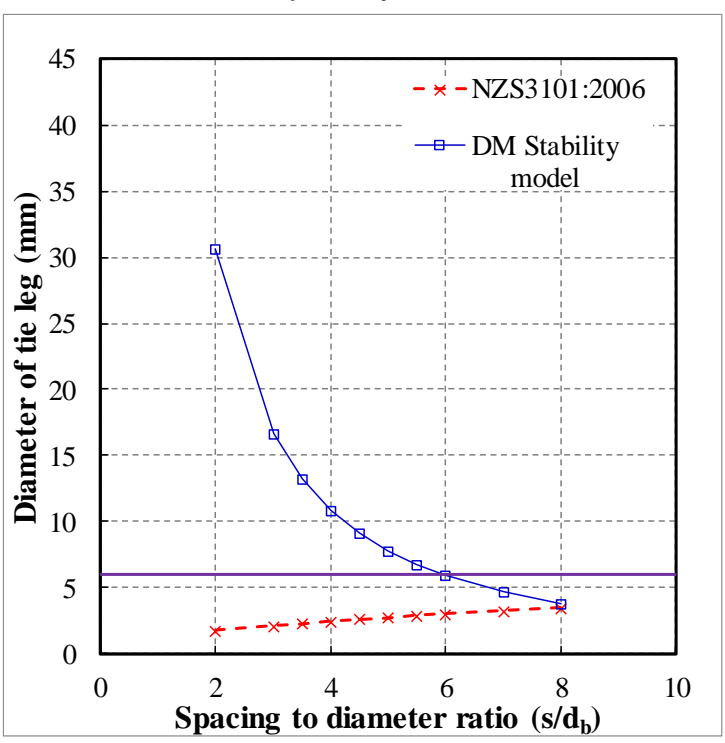

(d) Case-1: Buckling in X-direction

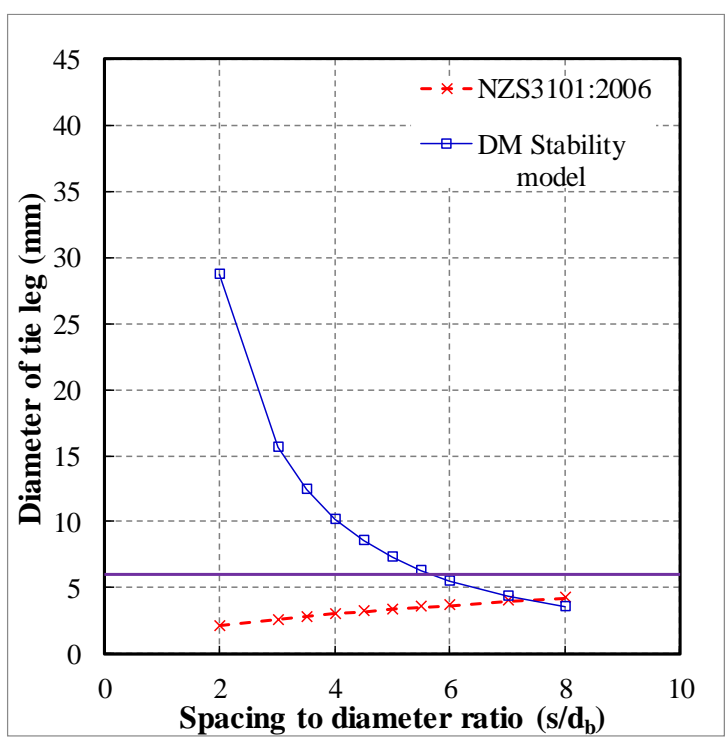

(e) Case-2: Buckling in Y-direction

Figure 2: Comparison of transverse reinforcement requirements as per NZS3101:2006 and DM stability model for wall RWB. 


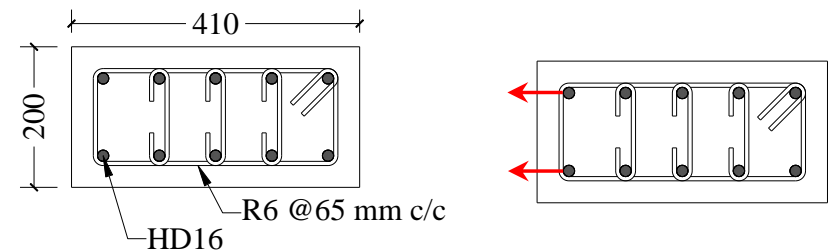

(a) Boundary zone of wall C10 (b) Bar buckling in X-direction

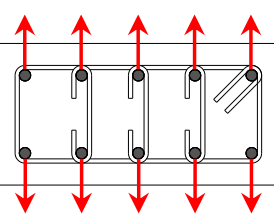

(c) Bar buckling in Y-direction

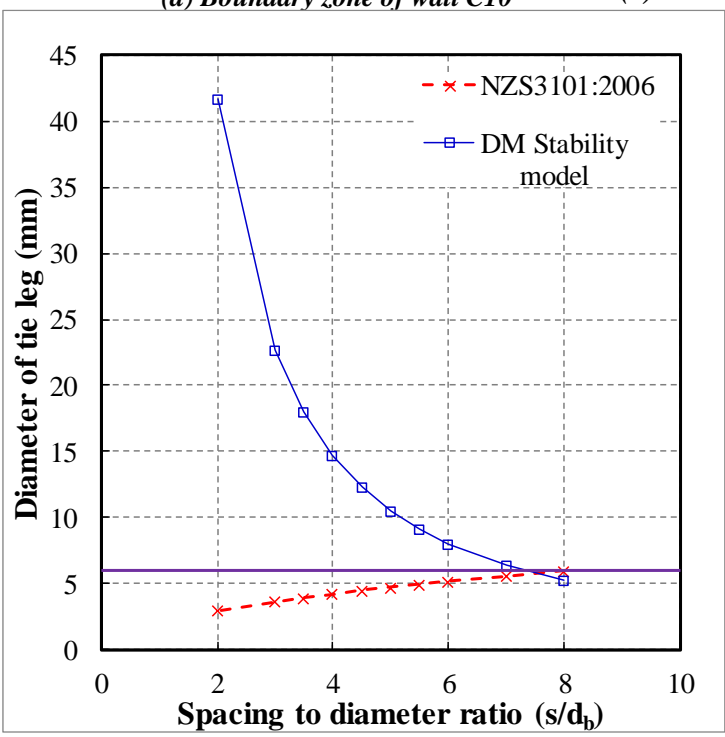

(d) Case-1: Buckling in X-direction

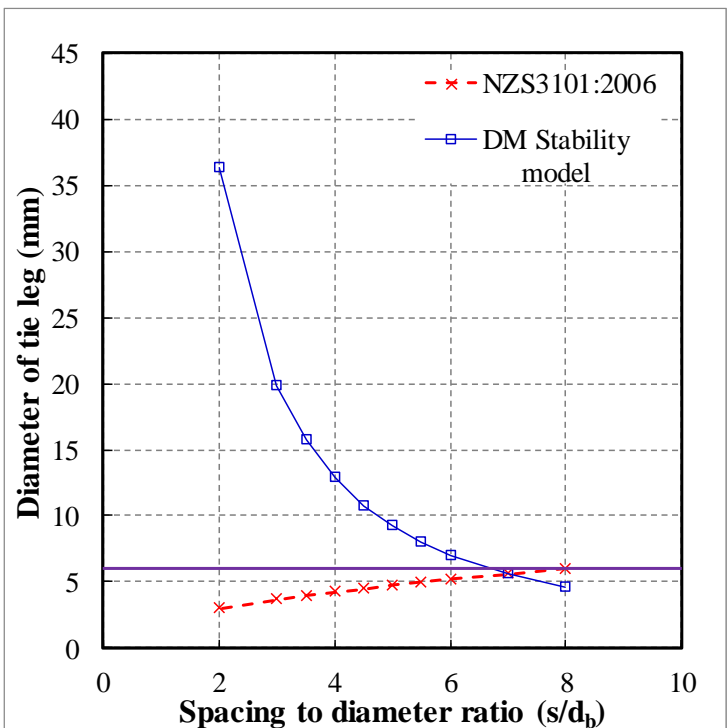

(e) Case-2: Buckling in Y-direction

Figure 3: Comparison of transverse reinforcement requirements as per NZS3101:2006 and DM stability model for wall C10.

\section{RECOMMENDATIONS FOR THE DESIGN OF ANTI- BUCKLING TIES}

In this section, improved anti-buckling design guidelines to restrict bar buckling in boundary elements of ductile $\mathrm{RC}$ walls are derived. Although modern standards recommend guidelines for the design of anti-buckling transverse reinforcement, experimental research on RC walls has highlighted their shortcomings in restricting buckling of longitudinal reinforcing bars to single tie spacing. Further, in modern design methodologies, including the recent mechanics-based design procedure proposed by Dhakal and Su [26], the effect of cyclic loading on bar buckling has not been incorporated. These design methodologies assume that bar buckling initiates under high compressive strain demands. This assumption holds true when RC members are subjected to monotonic demands, but experimental research reported in the literature has clearly shown that in RC structures bar buckling can initiate when the bar is still carrying tensile strains while unloading from large inelastic tensile strain demands. Hence, there is a need to incorporate the effect of tensile strain loading in designing antibuckling transverse reinforcement.

In capacity design, ductile RC structures are designed to sustain large deformation demands in critical regions. Therefore, it is imperative that non-ductile failure modes such as bar buckling and concrete crushing are delayed until the target design deformation is achieved. The design of anti-buckling reinforcement should primarily focus on two different aspects: (i) the transverse reinforcement should be adequate to restrict bar buckling to single tie spacing; and (ii) the compressive stress deterioration in reinforcing bars due to buckling should be limited until the designed inelastic deformation level is achieved. This can be achieved by effectively designing transverse reinforcement to restrict bar buckling to single tie spacing and then limiting the spacing of transverse reinforcement to avoid compressive stress deterioration in bars.

\section{Design of Transverse Reinforcement for Limiting Buckling to Single Tie Spacing}

To restrict bar buckling to single tie spacing, the axial stiffness of the tie legs in the direction of potential buckling $\left(\mathrm{k}_{\mathrm{t}}\right)$ should be greater than the critical lateral stiffness required to stop the bar from moving out at the tie location $\left(\mathrm{k}_{\mathrm{n}}\right)$ [12]. The stiffness required to restrict the bar buckling within single tie spacing evaluated using the stability model proposed by Dhakal and Maekawa [12] should be:

$$
\mathrm{k}_{\mathrm{t}} \geq \mathrm{k}_{\mathrm{n}} ; \frac{\mathrm{E}_{\mathrm{t}} \mathrm{A}_{\mathrm{t}}}{\mathrm{l}_{\mathrm{e}}} \frac{\mathrm{n}_{\mathrm{l}}}{\mathrm{n}_{\mathrm{b}}} \geq 0.75 \frac{\pi^{4} \mathrm{EI}}{\mathrm{s}^{3}}
$$

Rearranging the terms in Equation 9 and substituting for different design parameters, the critical length or maximum allowable tie leg length for restricting bar buckling to single tie spacing can be evaluated using Equation 10 , where $\mathrm{d}_{\mathrm{b}}$ and $\mathrm{d}_{\mathrm{t}}$ are the diameters of the longitudinal and transverse reinforcing bars, respectively.

$$
\frac{\mathrm{l}_{\mathrm{e}}}{\mathrm{d}_{\mathrm{t}}} \leq \frac{8.7}{\sqrt{\mathrm{f}_{\mathrm{y}}}}\left(\frac{\mathrm{s}}{\mathrm{d}_{\mathrm{b}}}\right)^{3}\left(\frac{\mathrm{d}_{\mathrm{t}}}{\mathrm{d}_{\mathrm{b}}}\right)\left(\frac{\mathrm{n}_{\mathrm{l}}}{\mathrm{n}_{\mathrm{b}}}\right)
$$

To evaluate the effect of different detailing parameters on the critical length (le of the tie legs, sensitivity studies are carried out on Equation 10. Length of the tie legs required to restrict buckling of longitudinal bars to single tie spacing for different grades of longitudinal reinforcing bars (Grade 300E and 500E) and different arrangements of longitudinal and transverse reinforcement are evaluated and compared. Figure 4 shows three typical arrangements of longitudinal and transverse reinforcement used in boundary elements of ductile RC walls. 
Figure 5 and Figure 6 show the variation of geometrical characteristic of the tie legs (i.e. ratio of the tie leg length and the diameter) as a function of transverse reinforcement spacing to longitudinal bar diameter ratio for Grade $300 \mathrm{E}$ and $500 \mathrm{E}$ bars, respectively. As can be seen from these figures, the critical length of the tie leg is dependent on both the longitudinal and transverse reinforcement detailing. Increasing the spacing of transverse reinforcement reduces the buckling-induced demand exerted by the longitudinal bar on the tie legs; therefore, increasing the spacing of transverse reinforcement results in a greater critical length of the tie legs. The length of the tie legs is directly proportional to the ratio of the diameters of transverse and longitudinal reinforcement; therefore, larger transverse to longitudinal bars ratio allows longer tie legs to be provided while maintaining the anti-buckling stiffness. The length of the tie legs is inversely proportional to the diameter of the longitudinal reinforcing bars. Increasing the bar diameter increases the bending stiffness of the longitudinal bar, which results in increased axial stiffness demands imposed on the tie legs by the longitudinal bars undergoing buckling. Therefore, as the diameter of the longitudinal bar increases the critical length of the tie leg reduces, implying that for longitudinal reinforcing bars of larger bar diameters, stiffer ties are required to restrict buckling within single tie spacing.
Similarly, increasing the yield strength of the longitudinal bars increases their effective flexural rigidity (EI evaluated using Equation 7 and imposes a higher buckling-induced demand on the transverse reinforcement. Therefore, to restrict bar buckling within single tie spacing, the tie length will have to reduce as the yield strength is increased. Furthermore, increasing the ratio of the number of tie legs $\left(\mathrm{n}_{1}\right)$ restraining the buckling prone longitudinal bars to the number of longitudinal bars undergoing simultaneous buckling $\left(\mathrm{n}_{\mathrm{b}}\right)$ increases the anti-buckling effectiveness of transverse reinforcement (as sown in Figure 7). Therefore, longer tie legs can be provided while still maintaining the anti-buckling resisting capacity of the tie legs if the number of longitudinal bars restrained by the legs is reduced.

Further, as can be seen from Figure 5 and Figure 6, the length of the tie legs required to restrict bar buckling to single tie spacing is significantly smaller than the typical tie leg length used in practice. For instance, in wall C10 (tested by Shegay et al. [32]) the length of the tie legs in the X-and Y-direction (as shown in Figure 3) to restrict bar buckling to single tie spacing should be less than $59 \mathrm{~mm}$ and $29.5 \mathrm{~mm}$, respectively. Similarly, in wall RWB (tested by Dashti et al. [4]) the length of the tie legs in the X-and Y-direction (as shown in Figure 2) should be less than $145 \mathrm{~mm}$ and $73 \mathrm{~mm}$, respectively.

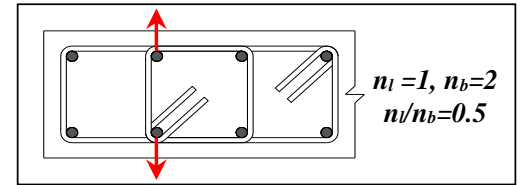

(a) Case-1

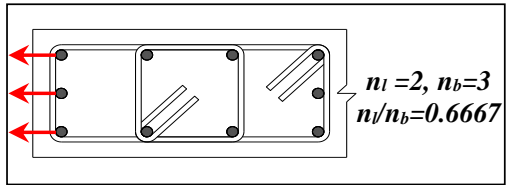

(b) Case-2

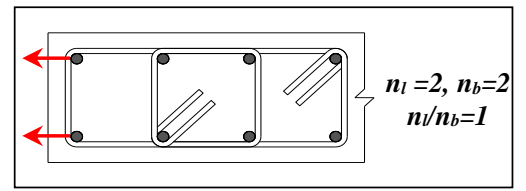

(c) Case-3

Figure 4: Typical configuration of longitudinal and transverse reinforcement in $R C$ walls.

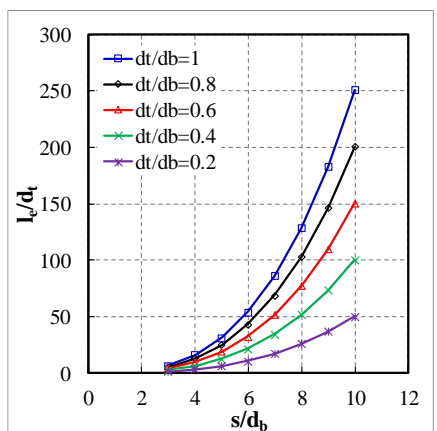

(a) $n / n_{b}=0.5$

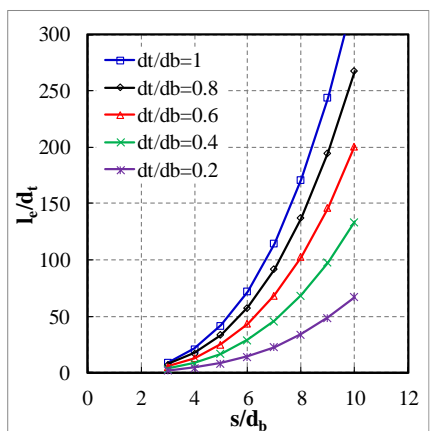

(b) $n_{1} / n_{b}=0.6667$

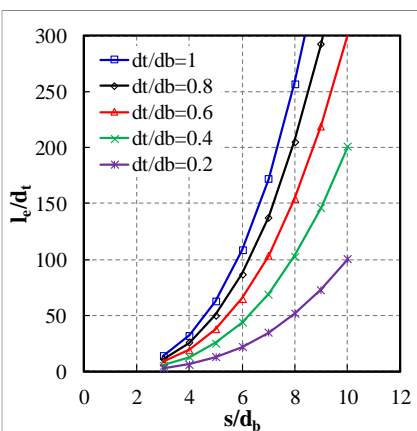

(c) $n_{1} / n_{b}=1$

Figure 5: Variation of the tie leg length as a function of transverse reinforcement spacing to longitudinal bar diameter ratio for Grade 300 E reinforcing bars.

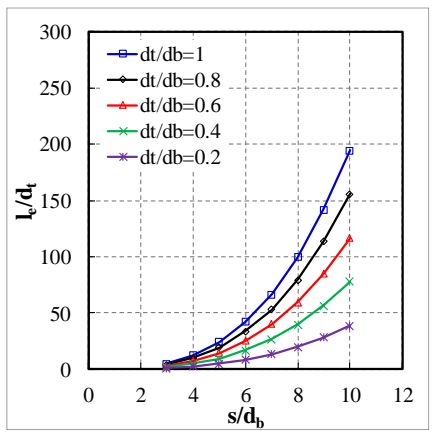

(a) $n_{l} / n_{b}=0.5$

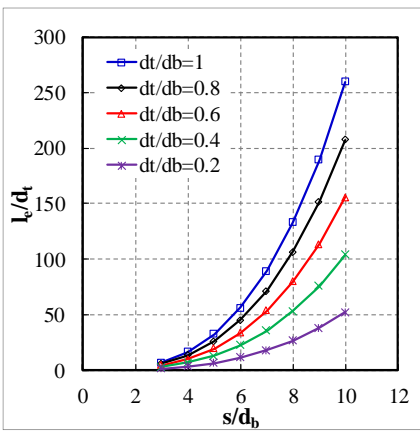

(b) $n_{l} / n_{b}=0.6667$

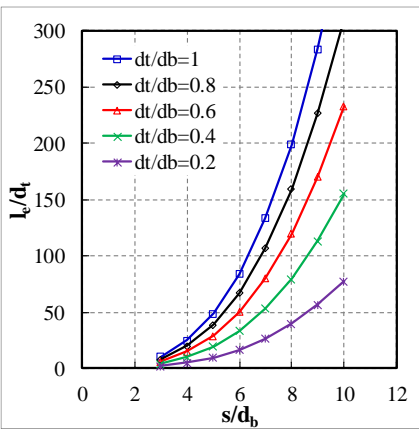

(c) $n_{l} / n_{b}=1$

Figure 6: Variation of the tie leg length as a function of transverse reinforcement spacing to longitudinal bar diameter ratio for Grade $500 E$ reinforcing bars. 


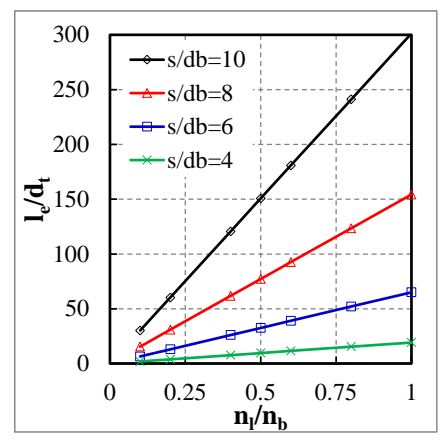

(a) Grade 300E, $d_{b} / d_{t}=0.6$

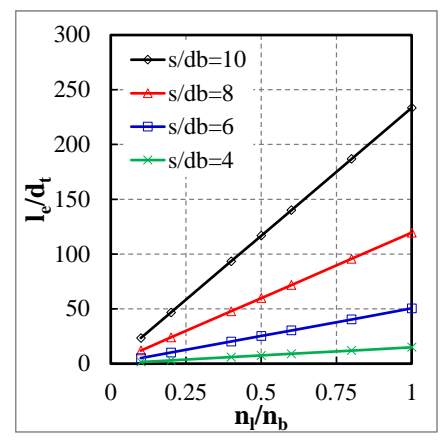

(b) Grade 500E, $d_{b} / d_{t}=0.6$

Figure 7: Variation of the tie leg length for different configuration of longitudinal and transverse reinforcement.

The axial stiffness of a tie leg is a function of its tie diameter and length, and it can be increased by either increasing the tie diameter or by reducing the tie leg length. In seismic design of $\mathrm{RC}$ structures, flexural and shear reinforcement are designed to satisfy flexural and shear demands. Thereafter, transverse reinforcement is designed to provide the required level of confinement. In the proposed design procedure, after the transverse reinforcement has been designed to satisfy the confinement requirement, it is proposed to check that the length of the tie legs in the direction of potential buckling is not longer than the critical tie length evaluated using Equation 10. If the length of the tie leg is greater than the critical length calculated using Equation 10, the axial stiffness of the tie leg needs to be increased by either reducing the length or increasing the area/diameter of the tie legs.

\section{Limiting Compressive Stress Deterioration in Reinforcing Bars}

Bar buckling reduces compressive stress capacity of longitudinal reinforcing bars, thereby reducing the moment capacity of critical sections and consequently affecting the lateral load-carrying capacity of RC structures. As highlighted earlier, in RC members subjected to cyclic loading, due to the presence of residual cracks the cracked concrete does not carry any compressive stresses, and the compressive stresses are solely carried by the longitudinal reinforcing bars. In RC structures, buckling length of reinforcing bars depends on the efficacy of transverse reinforcement to restrict the outward moving (i.e. buckling) tendency of longitudinal bars, whereas the reduction in compressive stress capacity of reinforcing bars due to buckling is a function of the bar's slenderness ratio (i.e. ratio of the total buckling length to the bar diameter). In addition, the initiation of buckling in longitudinal reinforcing bars also depends on the tensile and compressive strains imposed on the bars during seismic excitation. Therefore, in RC structures the reduction in a bar's compression capacity due to buckling can be controlled by limiting the spacing of transverse reinforcement along the length of the longitudinal reinforcing bars.

In the current methodology for the design of RC structures [17], it is assumed that bar buckling initiates under the influence of compressive strains, and therefore anti-buckling reinforcement is only required in regions susceptible to compressive yielding and limits the spacing of transverse reinforcement to $6 \mathrm{~d}_{\mathrm{b}}$. Bar buckling results in a sustained reduction of the compressive stress capacity of reinforcing bars; therefore, in the mechanicsbased design procedure proposed by Dhakal and Su [26] the strain corresponding to $15 \%$ reduction in compressive stress capacity was used as a criteria for the design of anti-buckling ties. Although it appears to be a logical design procedure, the effect of cyclic loading on the premature buckling of longitudinal bars was not considered in the formulation. As explained earlier, under cyclic loading bar buckling initiates while unloading from tensile strains and the strain corresponding to the initiation of compressive stress deterioration depends on the slenderness ratio of the bar. Therefore, the initiation of bar buckling in a RC wall depends on the combination of tensile and compressive strain demands in the critical regions of the wall. In this study, the effect of cyclic loading on buckling of longitudinal reinforcing bars is used as a criterion to limit the spacing of transverse reinforcement in the boundary regions of ductile RC walls.

To avoid the adverse effects of bar buckling on the lateral loadresisting capacity of RC structures, the compressive stress deterioration in reinforcing bars due to buckling should be limited until the designed drift demand is achieved. Therefore, in the developed methodology for the design of anti-buckling ties, it is proposed that the spacing and stiffness of transverse reinforcement shall be limited such that the buckling-induced stress deterioration is controlled at the maximum tensile and compressive strains expected in the critical regions.

Currently, NZS3101:2006 [17] limits the strain demands imposed on RC materials (concrete and reinforcing bars) due to plastic deformation by limiting the maximum curvature demands at plastic hinge regions. Therefore, it is proposed that the compressive stress deterioration in bars due to buckling should be controlled at the peak tensile and compressive strains expected at the limiting curvature. As per NZS3101:2006 [17], the curvatures at yield $\left(\phi_{\mathrm{y}}\right)$ and ultimate limit state $\left(\phi_{\max }\right)$ can be evaluated using Equations 11 and 12, respectively, where $E_{s}$ is the young modulus of reinforcing bars, $f_{y}$ is the yield strength of reinforcing bars (which shall be less than $425 \mathrm{MPa}$ ), $\mathrm{h}$ is the depth of the member and $\mathrm{k}_{\mathrm{d}}$ is a factor given in Table 3 . It should be noted that the yield curvature estimated using Equation 11 has been derived from moment-curvature analysis of rectangular RC walls $[33,34]$. Further, the maximum curvature estimated using Equation 12 represents a lower bound value from a set of experimental data on rectangular RC walls, and therefore provide a conservative estimate of the curvature demands at wall plastic hinges [35].

Table 3: Factor $k_{d}$ for limiting curvature in plastic hinges of ductile walls [17].

\begin{tabular}{ccc}
\hline Wall classification & $\begin{array}{c}\text { Limited ductile } \\
\text { plastic hinges }\end{array}$ & $\begin{array}{c}\text { Ductile plastic } \\
\text { hinges }\end{array}$ \\
\hline Singly reinforced & 5 & Not Applicable \\
\hline Doubly reinforced & 6 & 14 \\
\hline $\begin{array}{c}\text { Doubly reinforced } \\
\text { with confined } \\
\text { boundary elements }\end{array}$ & 9 & 16 \\
\hline
\end{tabular}


$\phi_{\mathrm{y}}=\frac{2 \mathrm{f}_{\mathrm{y}}}{\mathrm{E}_{\mathrm{s}} \mathrm{h}}$

$\phi_{\max }=\mathrm{k}_{\mathrm{d}} \phi_{\mathrm{y}}$

The performance of RC walls under seismic loading can be improved by limiting the buckling-induced compressive stress deterioration in bars at the limiting curvature allowed by NZS3101:2006 [17]. This implies that compressive stress deterioration in reinforcing bars unloading from the maximum tensile strain at the limiting curvature shall be controlled until the maximum compressive strain at the limiting curvature is reached. For this purpose, the maximum strain demands (tension and compression) expected at wall boundaries at the limiting curvature are evaluated. In addition, the strain ranges (i.e. difference between the maximum tensile strain and minimum compressive strain) that reinforcing bars are expected to undergo at the limiting curvature are also evaluated. The neutral axis depth in RC members typically depends on the member geometrical characteristics, reinforcement detailing, loading imposed on the member and damage sustained by the member during previous loading cycles. It has been wellestablished that neutral axis depth at the ultimate response rarely exceeds $50 \%$ of the member depth. Using this assumption, the maximum tensile and compressive strains expected at extreme wall fibres for different neutral axis depth positions at the limiting curvature demand are evaluated (see Table 4). In Table 4, $\mathrm{L}_{\mathrm{w}}$ is the wall length, $\mathrm{c}$ is the neutral axis depth, $f_{y}$ is the yield strength of reinforcing bars with an upper limit of $425 \mathrm{MPa}$ and $\varepsilon_{\mathrm{c}}$ and $\varepsilon_{\mathrm{t}}$ are the compressive and tensile strain demands at limiting curvature $\left(\phi_{\max }\right)$. As can be seen from this table, the strain range $\left(\Delta \varepsilon_{\mathrm{d}}\right)$ expected at the plastic hinges of ductile and limited ductile RC walls at the limiting curvature is independent of the neutral axis depth. Furthermore, the strain range demand $\left(\Delta \varepsilon_{\mathrm{d}}\right)$ at the limiting curvature is independent of the wall length. Therefore, hereafter the discussion about the maximum tensile and compressive strain demand expected in plastic hinges of RC walls is limited to the maximum strain range expected at the limiting curvature (i.e. $\Delta \varepsilon_{\mathrm{d}}$ ).

The buckling behaviour of reinforcing bars under compression has been well-defined by Dhakal and Maekawa [10]. In this bar buckling model, an intermediate strain was identified and it was analytically shown that compressive stresses start decreasing at a constant rate (equal to $0.2 \mathrm{E}_{\mathrm{s}}$ ) after this strain level until the residual stress capacity in compression (equal to $0.2 \mathrm{f}_{\mathrm{y}}$ ) is reached. Using this model, the strain range $(\Delta \varepsilon)$ that can be sustained by reinforcing bars with different slenderness ratios before undergoing buckling is evaluated by identifying the difference between the strain at origin and the intermediate point evaluated using Equation 13, where $\varepsilon_{\mathrm{i}}$ is the strain at the intermediate point, $\lambda$ is the buckling parameter given by Equation $14, \varepsilon_{y}$ is the yield strain, $\mathrm{L} / \mathrm{D}$ is the slenderness ratio and $f_{y}$ is the yield strength of the reinforcing bars.

$\frac{\varepsilon_{\mathrm{i}}}{\varepsilon_{\mathrm{y}}}=\max \left\{\begin{array}{c}55-2.3 \lambda \\ 7\end{array}\right.$

$\lambda=\frac{L}{D} \sqrt{\frac{f_{y}}{100}}$

$\Delta \varepsilon=\varepsilon_{\mathrm{i}}$

In the proposed guideline for the design of anti-buckling reinforcement, the spacing of transverse reinforcement along the longitudinal bars shall be restricted to ensure that under cyclic loading the initiation of sustained reduction of compressive stress in bars is delayed until the strain range demand $\left(\Delta \varepsilon_{\mathrm{d}}\right)$ at the limiting curvature is achieved (as given in Table 4). When unloaded from peak tensile strains, reinforcing bars unload almost elastically, followed by near-elastic loading of the bar in compression and subsequent yielding (as shown in Figure 8) [14,15]. In a reinforcing bar unloaded from a peak tensile strain of $\varepsilon_{\max }$, the sustained reduction in compressive stress due to buckling is initiated at $\varepsilon_{\min }$. Therefore, using Figure 8 , the strain range $\left(\Delta \varepsilon_{\mathrm{c}}\right)$ that could result in the initiation of the sustained stress deterioration in reinforcing bars subjected to cyclic loading can be evaluated using Equation 16.

$\Delta \varepsilon_{\mathrm{c}}=\Delta \varepsilon+\gamma \varepsilon_{\mathrm{y}}$

It should be noted that ideally the stiffness of the unloading curve from tension envelope is assumed equal to the elastic stiffness. However, past research on cyclic response of reinforcing bars have shown that the unloading stiffness is less than the elastic stiffness, and the reduction in the unloading stiffness is a function of the plastic strain accumulated in the reinforcing bars $[14,36]$. In addition to this, when subjected to cyclic loading, the loading stiffness of the bar in compression is slightly smaller than the elastic stiffness. Therefore, in this study the reduction in the unloading and reloading stiffness of the reinforcing bars is compensated by assuming factor $\gamma$ as two.

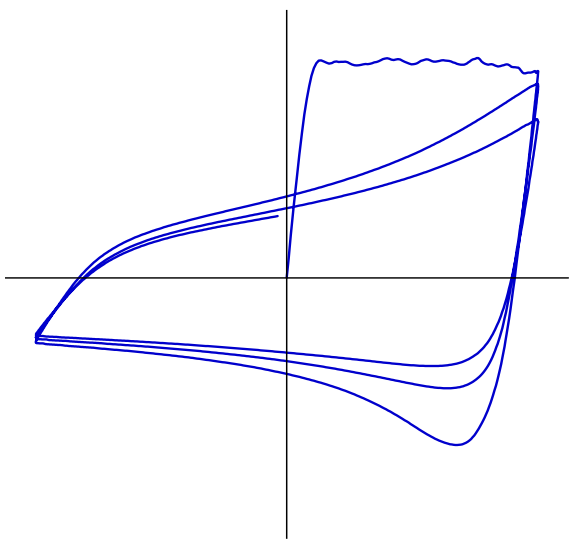

(a) Typical stress-strain response of a buckling prone reinforcing bar

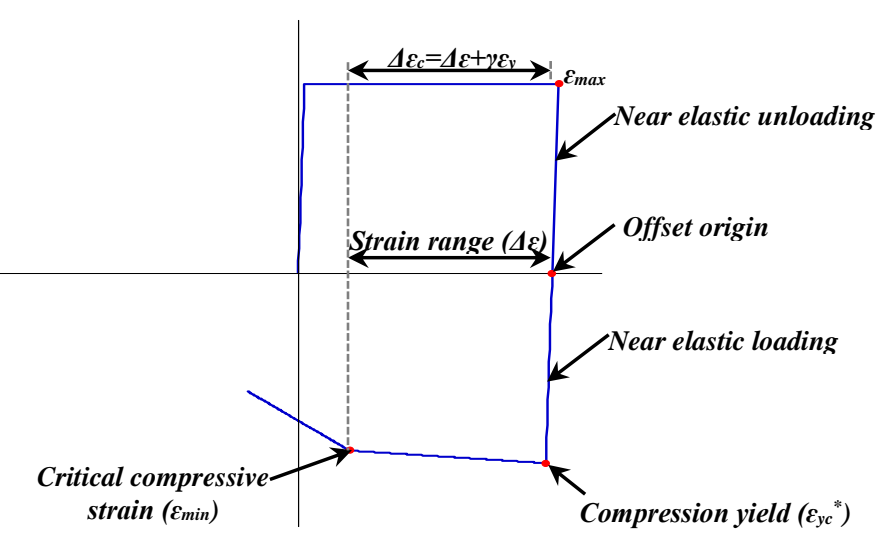

(b) Idealised stress-strain response of a reinforcing bar

Figure 8: Schematic illustration of bar buckling under cyclic loading. 
Table 4: Strain demands in RC walls at limiting curvature.

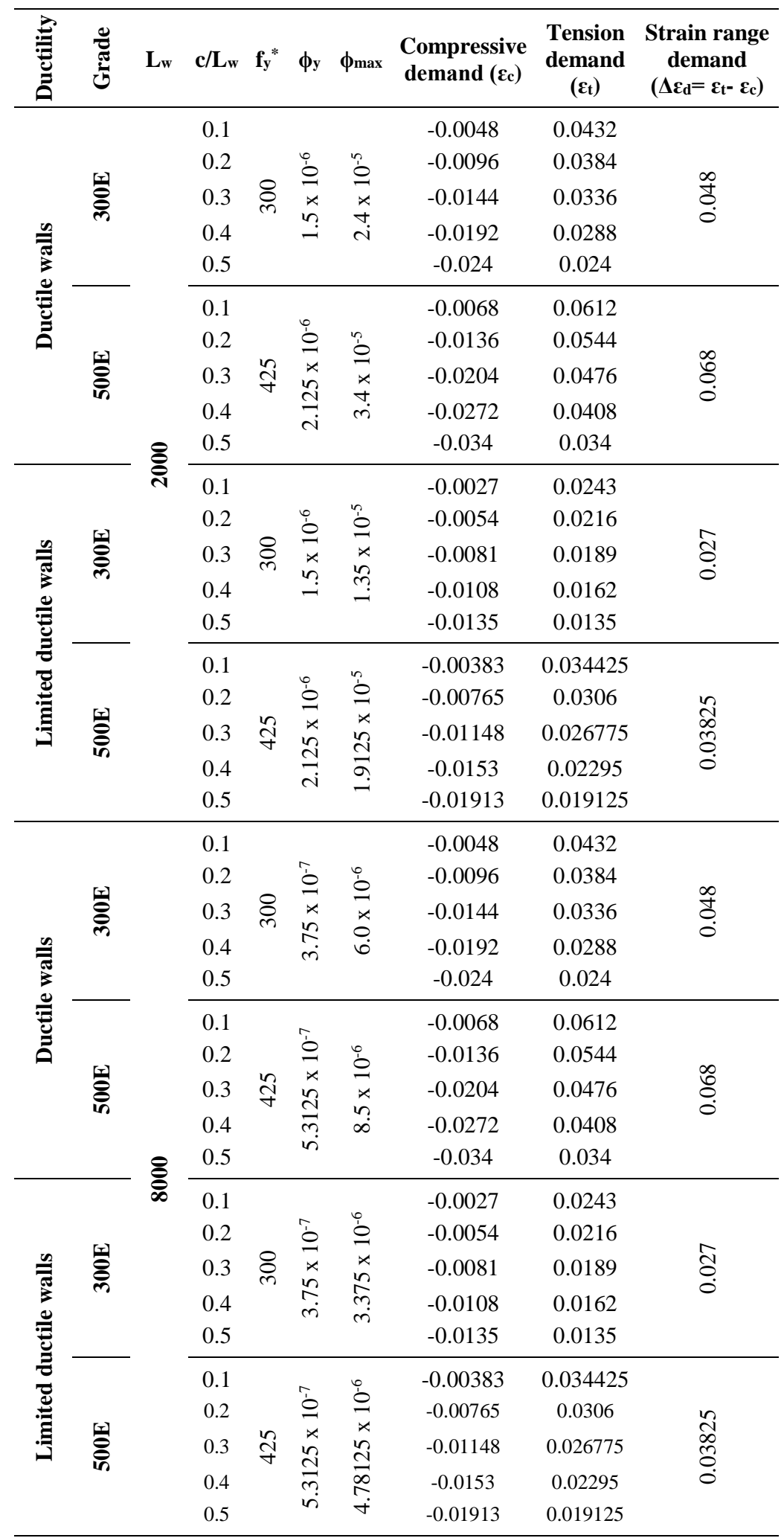

${ }^{*}$ Yield strength $\left(\mathrm{f}_{\mathrm{y}}\right) \leq 425 \mathrm{MPa}$

To evaluate the spacing limits for Grades $300 \mathrm{E}$ and $500 \mathrm{E}$ reinforcing bars, the strain range capacity $\left(\Delta \varepsilon_{c}\right)$ for reinforcing bars with different slenderness ratios were evaluated (using Equation 16, where $\Delta \varepsilon$ is given by Equation 15. Table 5 compares the strain range capacity $\left(\Delta \varepsilon_{\mathrm{c}}\right)$ of reinforcing bars with different slenderness ratios under cyclic loading and the maximum strain range demand $\left(\Delta \varepsilon_{\mathrm{d}}\right)$ expected at the limiting curvature. As can be inferred from Table 5, for ductile walls, slenderness ratios of $6 \mathrm{~d}_{\mathrm{b}}$ and $5.5 \mathrm{~d}_{\mathrm{b}}$ are required to sufficiently delay the compressive stress deterioration due to buckling under cyclic loading in Grade 300E and 500E bars, respectively. Similarly, for limited ductile walls with Grade 300E and 500E bars, slenderness ratios of $9 \mathrm{~d}_{\mathrm{b}}$ and $8 \mathrm{db}$ respectively, seem reasonable to limit the buckling-induced compressive stress deterioration until the maximum curvature demand is achieved. 
Table 5: Comparison of strain range capacity and demand at limiting curvature.

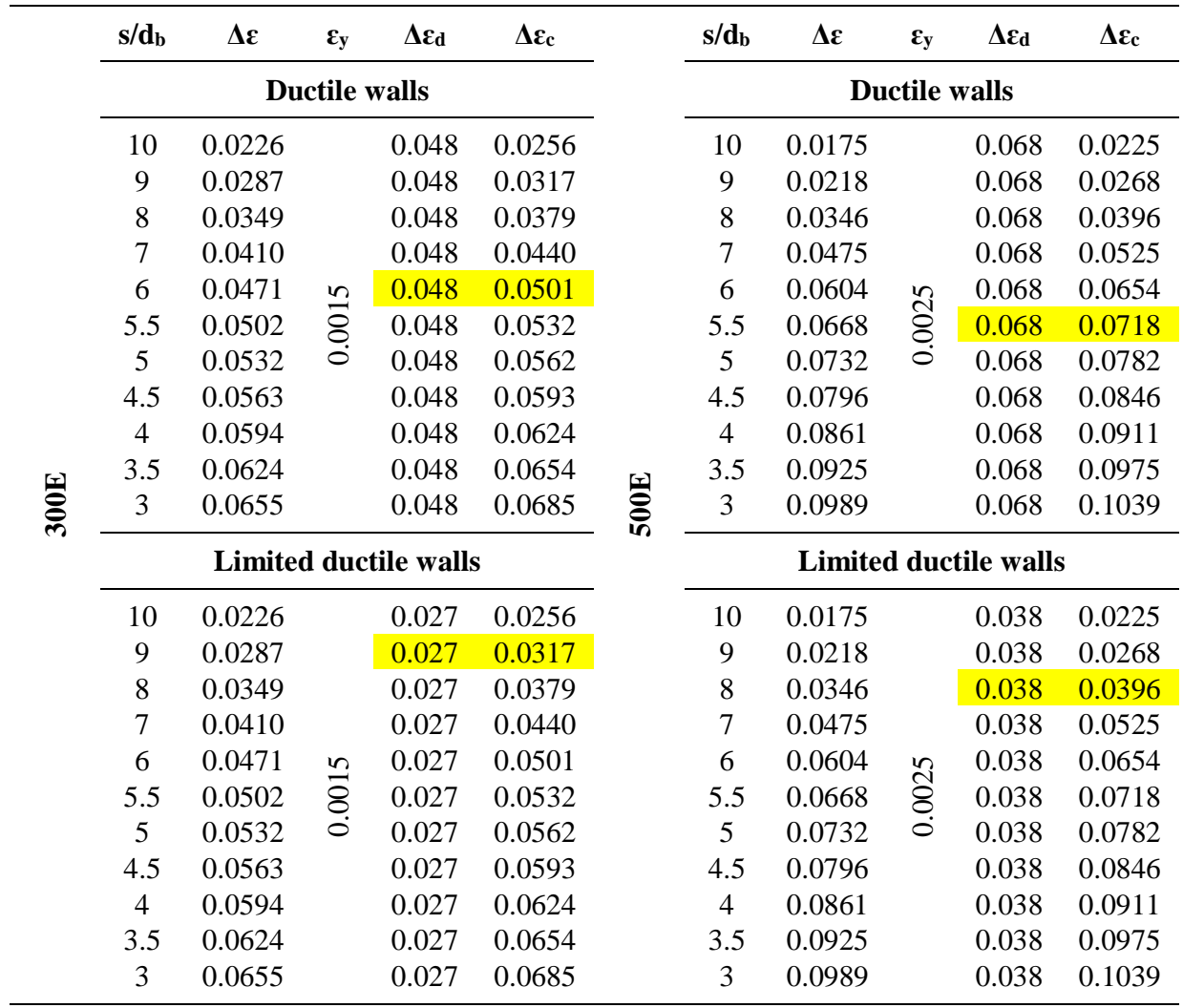

\section{Additional Requirements for Anti-buckling Reinforcement}

NZS3101:2006 [17] recommends that barring some exceptions, all boundary zone reinforcing bars shall be restricted agains buckling using anti-buckling reinforcement. According to NZS3101:2006 [17], if two reinforcing bars spaced less than $200 \mathrm{~mm}$ apart are restrained by a rectangular hoop leg or an intermediate tie, then any longitudinal bars between them are exempt from being restrained. However, the observations from experimental tests on RC walls designed according to New Zealand Standard highlight that unrestrained boundary zone reinforcing bars are highly susceptible to buckling under seismic loading $[5,6,37]$. In walls SWD-1 and SWD-2 [5,6], designed according to NZS3101:2006 [17], the unrestrained boundary zone reinforcing bars buckled. Moreover, buckling of unrestrained reinforcing bars permanently deformed the transverse reinforcement, thereby jeopardising both the antibuckling and confinement contribution of the transverse reinforcement. Figure 9 shows typical bar buckling and permanently deformed stirrup observed in wall SWD-1.

In the past, researchers $[27,38]$ have contemplated that in some cases, where an intermediate longitudinal reinforcing bar is left unrestrained between two longitudinal reinforcing bars that are restrained using hoops/stirrups, the front tie leg of the stirrup can provide resistance against buckling of the unrestrained longitudinal bar through its flexural stiffness as shown in Figure 10. In this figure, $l_{\mathrm{e}}$ is the tie length along the wall length, $\mathrm{l}_{\mathrm{eb}}$ is the length of the tie legs along the wall thickness and $\eta$ is the ratio of the lengths of the stirrup legs along the thickness and length of the wall (which is approximately equal to the aspect ratio of the rectangular stirrup). To compare the axial and bending stiffness of the tie legs, the ratio of the bending stiffness (evaluated using Equation 17) and the axial stiffness (evaluated using Equation 5) for different aspect ratio of stirrup/hoop (i.e. different $\eta$ factor) are evaluated and compared. For this purpose, the aspect ratio (i.e. $\eta$ ) of $1,0.5,0.33$ and 0.25 are adopted and the ratio of the bending and axial stiffness of tie legs is evaluated using Equation 18.

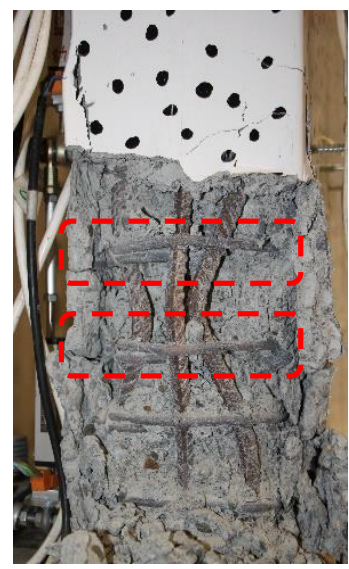

Figure 9: Bar buckling and stirrup deformation in wall SWD-1 [5].

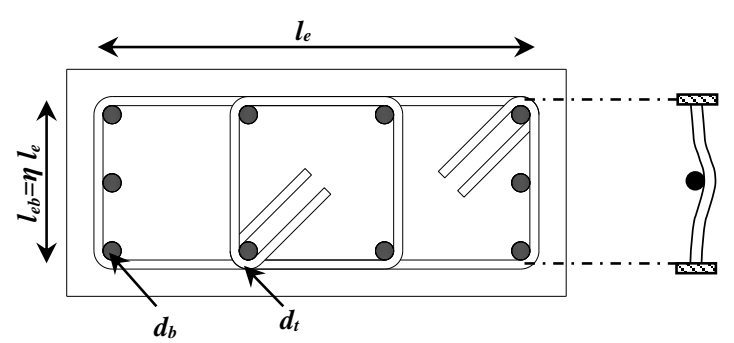

Figure 10: Flexural resistance against bar buckling provided by the tie leg.

Bending stiffness $\mathrm{k}_{\mathrm{b}}=\frac{192 \mathrm{E}_{\mathrm{t}} \mathrm{I}_{\mathrm{t}}}{1_{\mathrm{eb}}{ }^{3}}=\frac{192 \mathrm{E}_{\mathrm{t}} \mathrm{I}_{\mathrm{t}}}{\left(\eta \mathrm{l}_{\mathrm{e}}\right)^{3}}$

Stiffness ratio, $\frac{\mathrm{k}_{\mathrm{b}}}{\mathrm{k}_{\mathrm{t}}}=12\left(\frac{1}{\eta}\right)^{3}\left(\frac{\mathrm{d}_{\mathrm{t}}}{\mathrm{l}_{\mathrm{e}}}\right)^{2}$ 
Figure 11 shows the variation of the bar's bending and axial stiffness ratio $\left(\mathrm{kb}_{\mathrm{b}} / \mathrm{k}_{\mathrm{t}}\right)$ as a function of the ratio of the tie leg length and the tie diameter (i.e. $\mathrm{l}_{\mathrm{e}} / \mathrm{d}_{\mathrm{t}}$ ). As can be seen in Figure 11 , for different aspect ratio of the stirrup $(\eta)$, the bending stiffness of the tie leg is significantly smaller than its axial stiffness. In addition, for the ratio of tie leg length to bar diameter (i.e. $1_{\mathrm{e}} / \mathrm{d}_{\mathrm{t}}$ ) of 40 or larger, the bending stiffness of the tie legs is less than $50 \%$ of its axial stiffness, and for the most $1_{\mathrm{e}} / \mathrm{d}_{\mathrm{t}}$ ratios, the bending stiffness offered by the tie leg is less than $10 \%$ of bar axial stiffness. In addition, to ensure that the bending stiffness provided by the tie leg is equal to or greater than the axial stiffness provided by the tie leg, the ratio of tie leg length to tie diameter shall be less than $9.5,18$ and 27 for hoops with an aspect ratio of $0.5,0.33$ and 0.25 , respectively. Hence, it can be concluded that for practical series of stirrups/hoops the flexural resistance provided by the stirrups/hoops front legs against buckling is negligible in comparison to the axial resistance of the side legs and cannot be relied upon to provide adequate anti-buckling resistance. Therefore, it is recommended that all boundary zone longitudinal reinforcing bars shall be restrained in the direction of potential buckling using anti-buckling transverse reinforcement, unless the reinforcing bar is well-surrounded by concrete (i.e. internal reinforcing bar). For example, in the boundary zone of wall SWD-1 (shown in Figure 12) the bars in red shall be restrained against buckling using anti-buckling ties, while the reinforcing bar in green is well-surrounded by concrete and hence is exempted from being restrained.

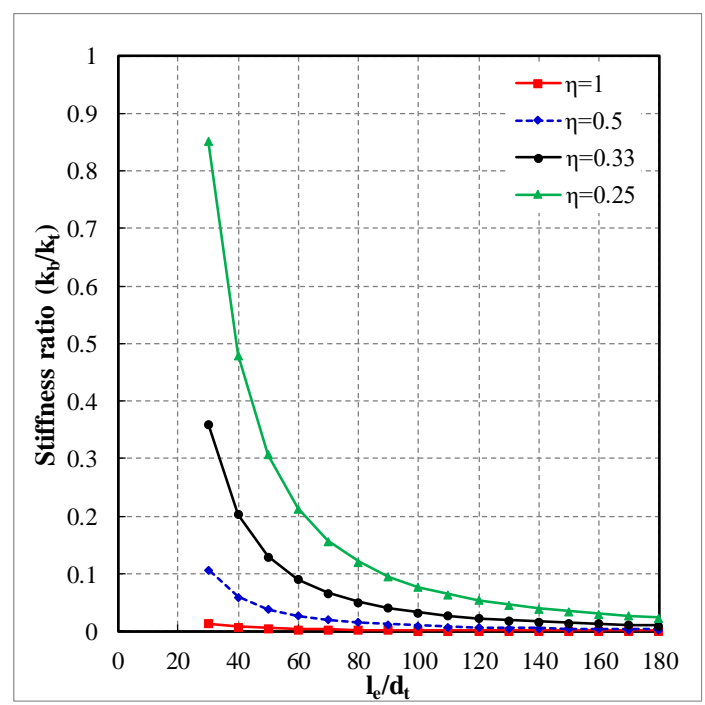

Figure 11: Tie leg axial and bending stiffness ratio.

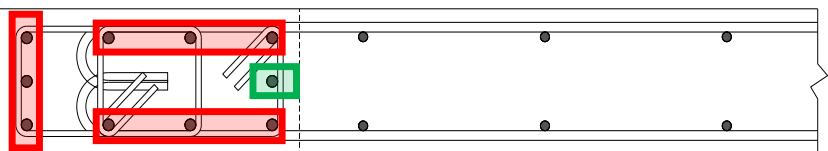

Figure 12: Boundary zone bars exempt from anti-buckling reinforcement.
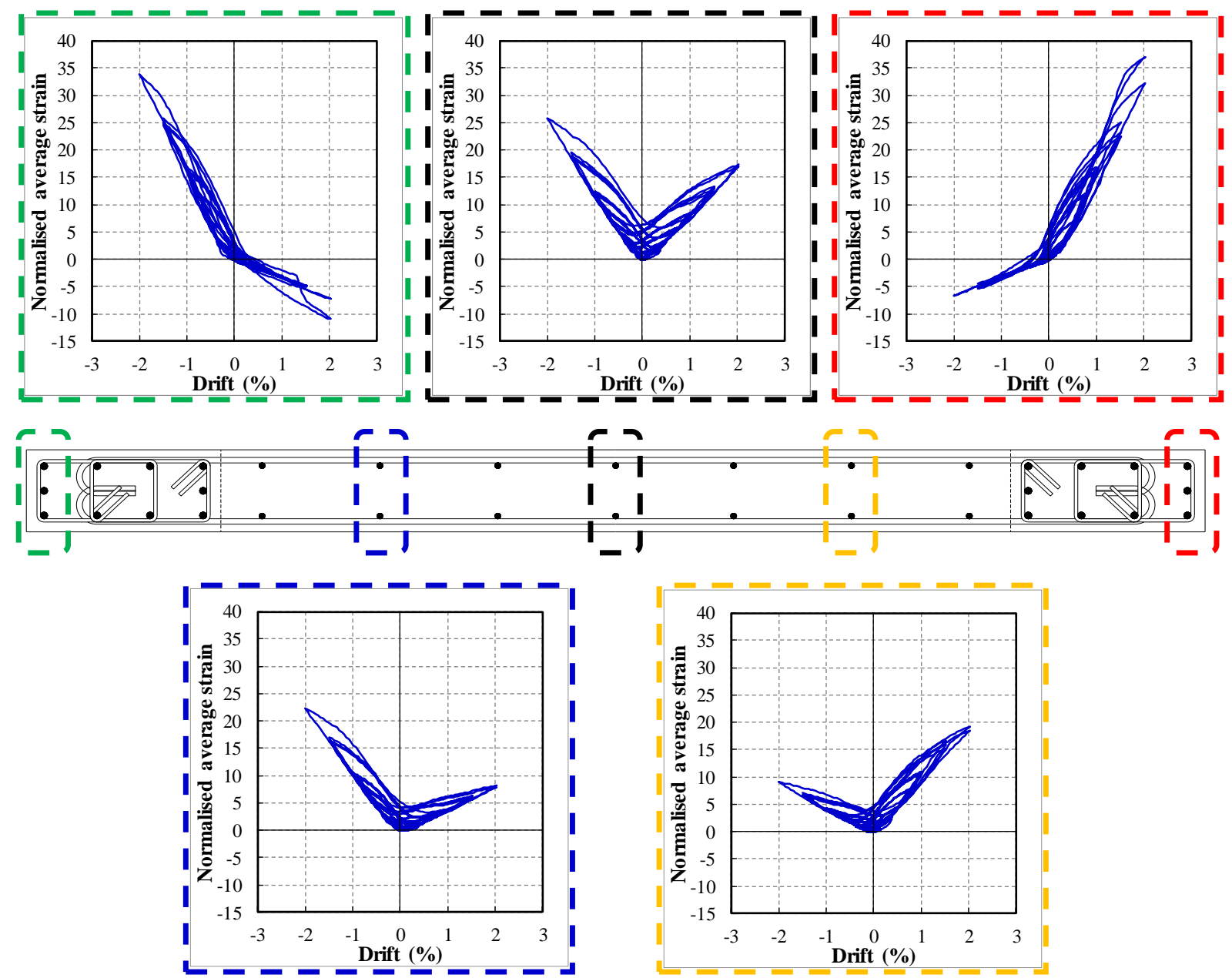

Figure 13: Strain history measured along the length of wall SWD-1 [5].

Most of the design codes except the recent revision of ACI-318 [19] does not impose any restrictions on the aspect ratio of the stirrup. According to ACI 318 [19,39], the aspect ratio of the hoops $(\eta)$ in the boundary elements of special structural walls should be greater than or equal to 0.5 . It is anticipated that this limitation will improve the concrete confinement and resistance provided by the hoop against buckling. However, authors are of this opinion that although this limitation on transverse reinforcement geometry will have a positive impact on the concrete confinement properties, this approach does not 
recognise the importance of the ratio of the tie leg length to diameter (or tie leg stiffness) on its anti-buckling resistance (as highlighted in previous sections), and therefore, will have minimal impact on the overall buckling resisting capacity of the transverse reinforcement. Additionally, as can be seen from Figure 11, for the stirrups/hoops with aspect ratio of 0.5 and more, the bending stiffness of the tie leg is less than $10 \%$ of its axial stiffness.

\section{Improving the Overall Seismic Response of RC Walls}

Longitudinal reinforcing bars in the web of walls are usually exempted from being restrained using anti-buckling ties. However, during the past earthquakes in New Zealand (201011) web reinforcing bars were also observed to have buckled in walls. Although these reinforcing bars are not subjected to large compressive strains, during seismic excitation they resist inelastic tensile strain demands that may cause them to prematurely buckle while unloading from peak tensile strains. As explained earlier, reinforcing bars unloaded from inelastic tensile strains prematurely yield in compression, and depending on the slenderness ratio of the bar, compressive stress reduction can initiate while the bar is still carrying tensile strains. For comparison, the strain histories measured at different regions along the length of wall SWD-1 [5] are compared in Figure 13. As can be seen from this figure, the strain histories experienced by longitudinal reinforcing bars in different regions of the wall are quite distinct. Boundary zone longitudinal reinforcing bars were subjected to large tensile and compressive strain demands, whereas longitudinal reinforcing bars in the wall web region were subjected to large tensile strain demands with negligible compressive strain demands. If these reinforcing bars are not restrained, buckling could initiate while unloading from peak tensile strain demands. Therefore, it is proposed that in addition to the boundary zone reinforcing bars, all wall web reinforcing bars in probable plastic hinge regions be restrained against buckling using the anti-buckling ties designed using the procedure proposed in this study. In addition to anti-buckling requirements, providing transverse reinforcement in the wall web also increases the compressive strength of concrete and hence improves the shear resistance of the wall. This guideline is in line with the intermittent design guidelines proposed after the 2010-11 Canterbury earthquakes in New Zealand [21].

Table 6: Summarising the implications of the proposed design procedure.

\begin{tabular}{|c|c|c|c|c|c|c|c|}
\hline Wall & As tested boundary zone detailing & $l_{e x} / d_{t^{a}}$ & $\mathbf{l e y}_{\text {ey }} / \mathbf{d t}^{\mathrm{a}}$ & $\mathbf{S} / \mathbf{d}_{\mathbf{b}} \mathbf{b}$ & $\mathbf{L x}_{\mathbf{x}} / \mathbf{d}_{\mathbf{b}}{ }^{\mathbf{c}}$ & $L_{y} / d_{b}{ }^{c}$ & $\begin{array}{l}\text { Modified detailing with same or } \\
\text { larger stirrup spacing }\end{array}$ \\
\hline $\begin{array}{l}\text { Wall C10 } \\
\text { [32] }\end{array}$ & 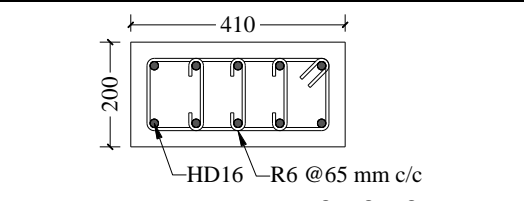 & 57 & 22 & 4.06 & 12.18 & 8.12 & 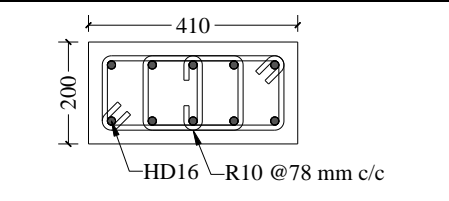 \\
\hline $\begin{array}{l}\text { Wall RWB } \\
\text { [4] }\end{array}$ & 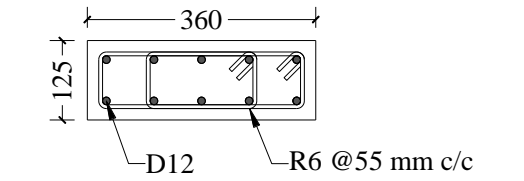 & 53 & 13.83 & 4.58 & 9.16 & 9.16 & 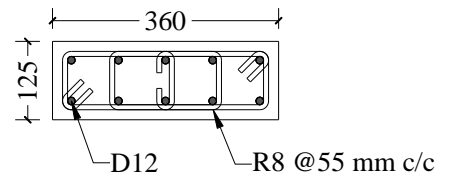 \\
\hline $\begin{array}{l}\text { Wall SWD- } \\
1[5,6]\end{array}$ & 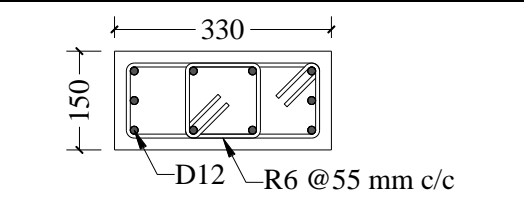 & 48 & 18 & 4.58 & 9.16 & 9.16 & 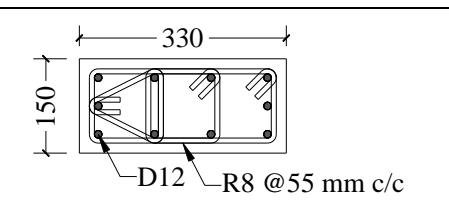 \\
\hline $\begin{array}{l}\text { Wall PW4 } \\
\text { [8] }\end{array}$ & 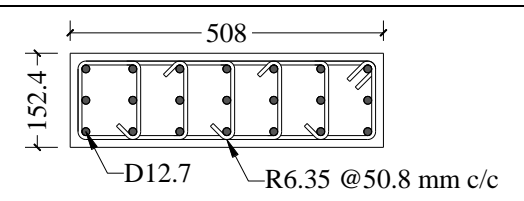 & 75 & 19 & 4.00 & 16 & 8 & 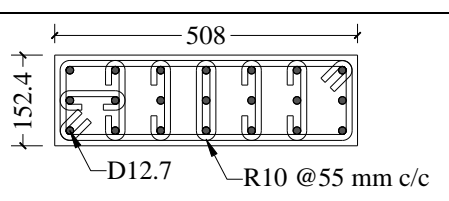 \\
\hline $\begin{array}{l}\text { Wall RW2 } \\
\text { [3] }\end{array}$ & 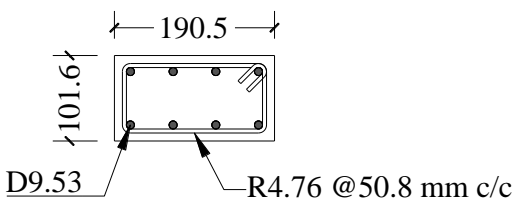 & 35.02 & 16.34 & 5.33 & 10.66 & 10.66 & 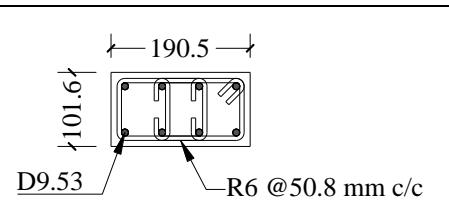 \\
\hline
\end{tabular}

\footnotetext{
${ }^{\text {a }}$ Ratio of the tie leg length and diameter in $\mathrm{X}$ and $\mathrm{Y}$ directions

${ }^{\mathrm{b}}$ Ratio of the transverse reinforcement spacing and tie leg diameter

${ }^{\mathrm{c}}$ Slenderness ratio of reinforcing bars (based on bar buckling mode) in $\mathrm{X}$ and $\mathrm{Y}$ directions.
} 


\section{IMPLICATIONS OF THE PROPOSED DESIGN PROCEDURE}

This section summarises the implications of the proposed design procedure on the detailing of anti-buckling transverse reinforcement. For this purpose, the boundary elements of ductile RC walls tested in the literature are adopted and their detailing are modified to ensure that the buckling of boundary zone longitudinal reinforcing bars is restricted to single tie spacing. Table 6 summarises the detailing of different wall boundary zones tested in the literature, expected slenderness ratio of the bar (i.e. the ratio of buckling length to the bar diameter) and improved detailing required to ensure bar buckling is restricted to single tie spacing. Note that herein the buckling mode of reinforcing bars is estimated using the stability model proposed by Dhakal and Maekawa [12], and the modified boundary zone detailing is proposed based on the design procedure outlined in this paper. As can be seen from Table 6, the boundary elements designed according to the current standards are susceptible to undergo buckling with buckling mode between 2 and 4 . Furthermore, the buckling mode of boundary zone reinforcing bars can be limited by utilising a combination of larger diameter ties, smaller tie leg length and transverse reinforcement spacing. It should be noted that the detailing requirements proposed in this paper to provide adequate buckling resistance do not substitute the confinement requirements outlined in different design standards.

To verify the efficacy of proposed design procedure to restrain bar buckling in ductile RC walls, the results from axial tests on $\mathrm{RC}$ prisms representing the boundary elements of $\mathrm{RC}$ wall designed according to NZS3101:2006 [17] are evaluated [9] and the observed buckling mode of longitudinal reinforcing bars in boundary zones with different transverse reinforcement detailing are compared. As can be seen from Table 7, using stirrups with increased axial stiffness (achieved by either increasing the diameter or reducing the length of the tie leg) and restraining all longitudinal bars improved the buckling resisting capacity of the stirrups. Prisms BZ-3-C2 and BZ-10-C2, that satisfied the proposed detailing requirements, bar buckling was restricted to single tie spacing as compared to prism BZ-1*-C2 where bar buckling spanning multiple tie spacing was observed. It should be noted that, Prism BZ-1 ${ }^{*}-\mathrm{C} 2$ satisfied all the antibuckling requirements prescribed by NZS3101:2006 [17]; however, did not satisfy the proposed detailing requirements, and therefore had poor bar buckling performance (as shown in Table 7).

\section{CONCLUSIONS}

Bar buckling spanning multiple tie spacing is a commonlyobserved failure mode restricting the deformation capacity of RC structures. In this paper, a detailed discussion of the antibuckling requirements prescribed by different design codes was presented, and their key limitations were identified. A popular bar stability model was adopted, and improved guidelines for the design of anti-buckling transverse reinforcement were proposed. It is anticipated that this improved detailing for transverse reinforcement in plastic hinges of ductile RC walls will delay unwanted compression-controlled failure modes and will avoid flexural walls failure until the design drift demands are met.

In the potential plastic hinges of RC walls, bar buckling can be controlled by effectively restraining the longitudinal reinforcing bars using anti-buckling stirrups/ties satisfying the following criteria:
Table 7: Experimental validation of the proposed design procedure [9].

\begin{tabular}{|c|c|c|}
\hline $\begin{array}{l}\text { Boundary } \\
\text { Zone }\end{array}$ & Detailing & $\begin{array}{l}\text { Observed bar } \\
\text { buckling mode }\end{array}$ \\
\hline
\end{tabular}
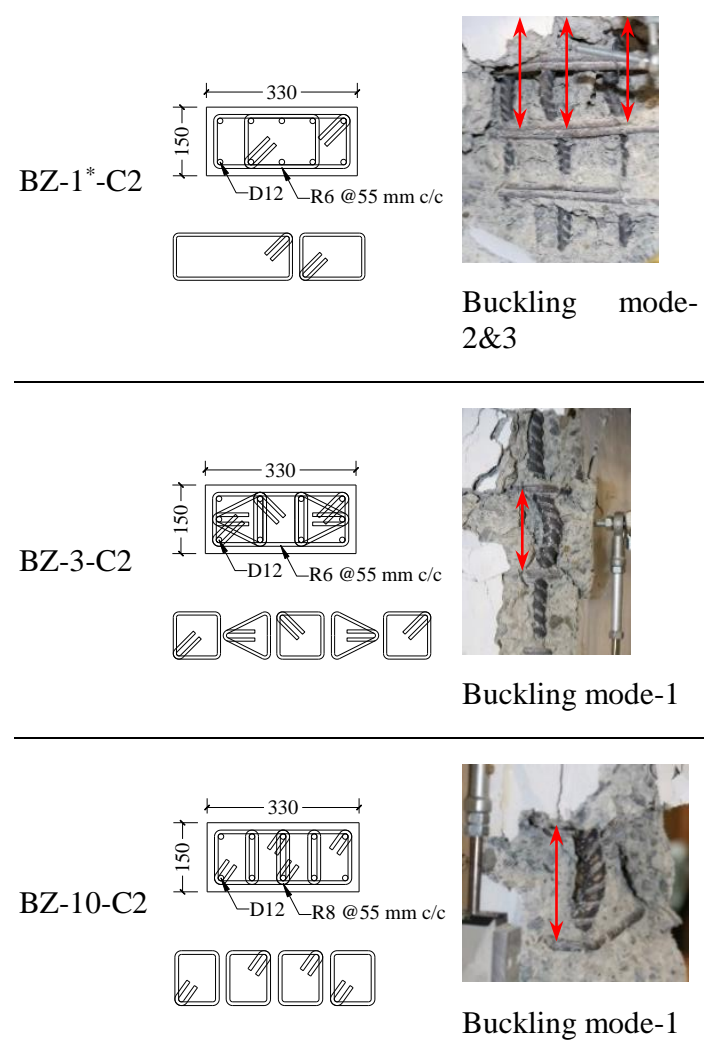

1. For a given longitudinal and transverse reinforcement detailing, the length of the tie legs in the direction of potential buckling shall be less than the critical length evaluated as:

$$
\frac{\mathrm{l}_{\mathrm{e}}}{\mathrm{d}_{\mathrm{t}}} \leq \frac{8.7}{\sqrt{\mathrm{f}_{\mathrm{y}}}}\left(\frac{\mathrm{s}}{\mathrm{d}_{\mathrm{b}}}\right)^{3}\left(\frac{\mathrm{d}_{\mathrm{t}}}{\mathrm{d}_{\mathrm{b}}}\right)\left(\frac{\mathrm{n}_{1}}{\mathrm{n}_{\mathrm{b}}}\right)
$$

2. To delay and limit the buckling-induced compressive stress deterioration in reinforcing bars under cyclic loading, the spacing of transverse reinforcement along the longitudinal reinforcing bars shall be:

$$
\text { Ductile walls: Spacing, } s< \begin{cases}6 \mathrm{~d}_{\mathrm{b}} & \text { Grade } 300 \mathrm{E} \\ 5.5 \mathrm{~d}_{\mathrm{b}} & \text { Grade } 500 \mathrm{E}\end{cases}
$$

$$
\text { Limited ductile walls: Spacing, } s<\left\{\begin{array}{l}
9 \mathrm{~d}_{\mathrm{b}} \text { Grade } 300 \mathrm{E} \\
8 \mathrm{~d}_{\mathrm{b}} \text { Grade } 500 \mathrm{E}
\end{array}\right.
$$

3. Transverse reinforcement in the form of stirrups and ties shall be suitably arranged such that all longitudinal reinforcing bars in the potential plastic hinge regions are effectively restricted against buckling using anti-buckling ties designed using (1) and (2).

4. With no exception, only the internal reinforcing bars wellsurrounded by concrete shall be exempt from being restrained using anti-buckling reinforcement.

5. To limit buckling, all reinforcing bars in the wall web shall be restrained using anti-buckling ties designed using (1), (2) and (3), unless they are exempt from being restrained according to (4). 


\section{ACKNOWLEDGEMENTS}

The authors would like to acknowledge the financial assistance provided by the Ministry of Business, Innovation and Employment (MBIE) and the Quake Centre at University of Canterbury for carrying out the research. This project was (partially) supported by QuakeCoRE, a New Zealand Tertiary Education Commission-funded Centre. The guidance provided by Dr Farhad Dashti is greatly appreciated.

\section{REFERENCES}

1 Wallace JW, Massone LM, Bonelli P, Dragovich J, Lagos R, Luders C and Moehle J (2012). "Damage and implications for seismic design of RC structural wall buildings". Earthquake Spectra, 28: S281-S299. https://doi.org/10.1193\%2F1.4000047

2 Sritharan S, Beyer K, Henry RS, Chai YH, Kowalsky M and Bull D (2014). "Understanding poor seismic performance of concrete walls and design implications". Earthquake Spectra, 30(1): 307-334.

https://doi.org/10.1193\%2F021713EQS036M

3 Thomsen JH and Wallace JW (2004). "Displacement-based design of slender reinforced concrete structural wallsexperimental verification". ASCE Journal of Structural Engineering, 130(4): 618-630. https://doi.org/10.1061/(ASCE)07339445(2004)130:4(618)

4 Dashti F, Dhakal RP and Pampanin S (2017). "Tests on slender ductile structural walls designed according to New Zealand Standard". Bulletin of the New Zealand Society for Earthquake Engineering, 50(4): 504-516. https://doi.org/10.5459/bnzsee.50.4.504-516

5 Tripathi M, Dhakal RP and Dashti F (2019). "Bar buckling in ductile RC walls with different boundary zone detailing: Experimental investigation". Engineering Structures, 198. https://doi.org/10.1016/j.engstruct.2019.109544

6 Tripathi M, Dhakal RP and Dashti F (2020). "Nonlinear cyclic behaviour of high-strength ductile RC walls: Experimental and numerical investigations". Engineering Structures, 222. https://doi.org/10.1016/j.engstruct.2020.111116

7 Dashti F, Tripathi M, Dhakal RP and Pampanin S (2020). "A parametric study on out-of-plane instability of doubly reinforced structural walls. Part II: Experimental investigation". Bulletin of Earthquake Engineering, 18(11): 5193-5220. https://doi.org/10.1007/s10518-020-00898-w

8 Birely AC (2012). "Seismic Performance of Slender Reinforced Concrete Structural Walls". PhD Dissertation, University of Washington, Seattle. http://hdl.handle.net/1773/22577

9 Tripathi M, Dhakal RP, Dashti F and Gokhale R (2020). "Axial response of rectangular RC prisms representing the boundary elements of ductile concrete walls". Bulletin of Earthquake Engineering, 18(9): 4387-4420. https://doi.org/10.1007/s10518-020-00868-2

10 Dhakal RP and Maekawa K (2002). "Modeling for postyield buckling of reinforcement". ASCE Journal of Structural Engineering, 128(9): 1139-1147. https://doi.org/10.1061/(ASCE)07339445(2002)128:9(1139)

11 Dhakal RP and Maekawa K (2002). "Path-dependent cyclic stress-strain relationship of reinforcing bar including buckling". Engineering Structures, 24(11): 1383-1396. https://doi.org/10.1016/S0141-0296(02)00080-9
12 Dhakal RP and Maekawa K (2002). "Reinforcement stability and fracture of cover concrete in reinforced concrete members". ASCE Journal of Structural Engineering, 128(10): 1253-1262.

https://doi.org/10.1061/(ASCE)07339445(2002)128:10(1253)

13 Kashani MM, Lowes LN, Crewe AJ and Alexander NA (2015). "Phenomenological hysteretic model for corroded reinforcing bars including inelastic buckling and low-cycle fatigue degradation". Computers and Structures, 156: 5871. https://doi.org/10.1016/j.compstruc.2015.04.005

14 Tripathi M (2020). "Bar Buckling in Ductile Reinforced Concrete Walls: Causes, Consequences and Control". PhD Dissertation, University of Canterbury, Christchurch. http://dx.doi.org/10.26021/1859

15 Tripathi M, Dhakal RP, Dashti F and Massone LM (2018). "Low-cycle fatigue behaviour of reinforcing bars including the effect of inelastic buckling". Construction and Building Materials, 190: 1226-1235.

https://doi.org/10.1016/j.conbuildmat.2018.09.192

16 Tripathi M, Dhakal RP, Dashti F and Massone LM (2019). "Low-cycle fatigue damage of buckling prone reinforcing bars". Pacific Conference on Earthquake Engineering and Annual NZSEE Conference, Auckland, New Zealand. http://db.nzsee.org.nz/2019/Oral/11A.02\%20Dhakal.pdf

17 SNZ (2006). " NZS 3101: Concrete Structures StandardThe Design of Concrete Structures". Standards New Zealand, Wellington.

https://shop.standards.govt.nz/catalog/3101.1\%7C2\%3A2 006\%28NZS\%29/view

18 ACI (2014). " Building Code Requirements for Structural Concrete (ACI 318-14)". American Concrete Institute, Farmington Hills, MI.

19 ACI (2019). "Building Code Requirements for Structural Concrete (ACI 318-19)". American Concrete Institute, Farmington Hills, MI.

https://www.concrete.org/store/productdetail.aspx?ItemID =31819HC\&Format=HARD_COPY\&Language=English \&Units=US_Units

20 CEN (2005). "Eurocode-8: Design of Structures for Earthquake Resistance-Part 1: General Rules, Seismic Actions and Rules for Buildings". European Committee for Standardisation, Brussles.

21 SESOC (2013). "Design of Conventional Structural Systems following the Canterbury Earthquakes: Interim Design Guidelines".

https://www.sesoc.org.nz/library/guidelines/sesoc-interimdesign-guidance-design-of-conventional-structuralsystems-following-the-canterbury-earthquakes/

22 Sheikh SA and Uzumeri SM (1980). "Strength and ductility of tied concrete columns". 106(ASCE Proceeding). https://www.researchgate.net/publication/279577120_Stre ngth_and_Ductility_of_Tied_Concrete_Columns

23 Mander JB, Priestley MJN and Park R (1988). "Theoretical stress-strain model for confined concrete". ASCE Journal of Structural Engineering, 114(8): 1804-1826. https://doi.org/10.1061/(ASCE)07339445(1988)114:8(1804)

24 Mander JB, Priestley MJN and Park R (1988). "Observed stress-strain behavior of confined concrete". ASCE Journal of Structural Engineering, 114(8): 1827-1849. https://doi.org/10.1061/(ASCE)07339445(1988)114:8(1827) 
25 Saatcioglu M and Razvi SR (1992). "Strength and ductility of confined concrete". ASCE Journal of Structural Engineering, 118(6): 1590-1607. https://doi.org/10.1061/(ASCE)07339445(1992)118:6(1590)

26 Dhakal RP and Su J (2018). "Design of transverse reinforcement to avoid premature buckling of main bars". Earthquake Engineering and Structural Dynamics, 47(1): 147-168. https://doi.org/10.1002/eqe.2944

27 Bresler B and Gilbert P (1961). Tie requirements for reinforced concrete columns". ACI Journal Proceedings. http://dx.doi.org/10.14359/7997

28 Pantazopoulou SJ (1998). "Detailing for reinforcement stability in RC members". ASCE Journal of Structural Engineering, 124(6): 623-632. https://doi.org/10.1061/(ASCE)07339445(1998)124:6(623)

29 Massone LM and Lopez EE (2014). "Modeling of reinforcement global buckling in RC elements". Engineering Structures, 59: 484-494. https://doi.org/10.1016/j.engstruct.2013.11.015

30 Dhakal RP (2006). "Post-peak response analysis of SFRC columns including spalling and buckling". Structural Engineering and Mechanics, 22(3): 311-330. http://dx.doi.org/10.12989/sem.2006.22.3.311

31 Sato Y and Ko H (2007). "Experimental investigation of conditions of lateral shear reinforcements in RC columns accompanied by buckling of longitudinal bars". Earthquake Engineering and Structural Dynamics, 36(12): 1685-1699. https://doi.org/10.1002/eqe.712

32 Shegay AV, Motter CJ, Elwood KJ, Henry RS, Lehman DE and Lowes LN (2018). "Impact of axial load on the seismic response of rectangular walls". ASCE Journal of Structural Engineering, 144(8). https://doi.org/10.1061/(ASCE)ST.1943-541X.0002122
33 Priestley MJN and Kowalsky M (1998). "Aspects of drift and ductility capacity of rectangular cantilever structural walls". Bulletin of the New Zealand Society for Earthquake Engineering, 31(2): 73-85.

https://doi.org/10.5459/bnzsee.31.2.73-85

34 Hoult RD, Goldsworthy HM and Lumantarna E (2018). "Plastic hinge analysis for lightly reinforced and unconfined concrete structural walls". Bulletin of Earthquake Engineering, 16(10): 4825-4860. https://doi.org/10.1007/s10518-018-0369-x

35 Dhakal RP and Fenwick RC (2008). "Detailing of plastic hinges in seismic design of concrete structures". ACI Structural Journal, 105(6). http://hdl.handle.net/10092/4190

36 Dodd L and Restrepo-Posada J (1995). "Model for predicting cyclic behavior of reinforcing steel". ASCE Journal of Structural Engineering, 121(3): 433-445. https://doi.org/10.1061/(ASCE)07339445(1995)121:3(433)

37 Tripathi M, Dhakal RP and Dashti F (2019). "Non-linear cyclic response of concrete walls with different transverse reinforcement detailing". 12th Canadian Conference on Earthquake Engineering, Quebec City, Canada. https://hdl.handle.net/10092/101148

38 Scribner CF (1986). "Reinforcement buckling in reinforced-concrete flexural members". Journal of the American Concrete Institute, 83(6): 966-973. http://dx.doi.org/10.14359/2648

39 Moehle JP (2019). "Key changes in the 2019 edition of the ACI Building Code (ACI 318-19)". Concrete International, 41(8): 21-27. https://www.concrete.org/publications/internationalconcret eabstractsportal.aspx?m=details\&i=51719093 